Article

\title{
Three-Phase High-Power and Zero-Current-Switching OBC for Plug-In Electric Vehicles
}

\section{Cheng-Shan Wang ${ }^{1}$, Wei Li ${ }^{1, \dagger}$, Zhun Meng ${ }^{1, \dagger}$, Yi-Feng Wang ${ }^{1, *}$ and Jie-Gui Zhou ${ }^{2}$}

1 School of Electrical Engineering and Automation, Tianjin University, Tianjin 300072, China; E-Mails: cswang@tju.edu.cn (C.-S.W.); liweitju@hotmail.com (W.L.); quakermaster@hotmail.com (Z.M.)

2 The Third Railway Survey and Design Institute Group Corporation, Tianjin 300251, China; E-Mail: zhou.jiegui@163.com

$\dagger$ These authors contributed equally to this work.

* Author to whom correspondence should be addressed; E-Mail: wayif@tju.edu.cn; Tel.: +86-185-2206-2559; Fax: +86-22-2740-1479.

Academic Editor: Joeri Van Mierlo

Received: 4 May 2015 / Accepted: 23 June 2015 / Published: 30 June 2015

\begin{abstract}
In this paper, an interleaved high-power zero-current-switching (ZCS) onboard charger (OBC) based on the three-phase single-switch buck rectifier is proposed for application to plug-in electric vehicles (EVs). The multi-resonant structure is used to achieve high efficiency and high power density, which are necessary to reduce the volume and weight of the OBC. This study focuses on the border conditions of ZCS converting with a battery load, which means the variation ranges of the output voltage and current are very large. Furthermore, a novel hybrid control method combining pulse frequency modulation (PFM) and pulse width modulation (PWM) together is presented to ensure a driving frequency higher than $10 \mathrm{kHz}$, and this will reduce the unexpected inner resonant power flow and decrease the total harmonic distortion (THD) of the input current under a light load at the end of the charging process. Finally, a prototype is established, and experiments are carried out. According to the experimental results, the conversion efficiency is higher than $93.5 \%$, the THD about $4.3 \%$ and power factor (PF) 0.98 under the maximum power output condition. Besides, a three-stage charging process is also carried out the experimental platform.
\end{abstract}

Keywords: onboard charger; buck converter; zero-current-switching; electric vehicle 


\section{Introduction}

Due to the environmental and energy crises, more and more researchers are paying attention to novel energy vehicles, such as electric vehicles (EVs) and hybrid electric vehicles (HEVs). It is widely known that battery chargers play a critical role in the development of EVs, and the charging time and lifetime of batteries are closely related to the characteristics of the chargers. A battery charger must be efficient and reliable, with low cost, low volume and low weight, as well as high-power output capability [1-5]. Most of the chargers can be divided into two types: onboard chargers (OBCs) and off-board chargers (FBCs). Generally, FBCs are located in charging station, which are suitable for fast charging. However, the expensive construction cost and limited locations (mostly in big cities) have limited the wide application of FBCs. Different from FBCs, OBCs mean taking the chargers with the vehicles and thus having relatively higher flexibility, which makes it possible to get charged through a socket. Thereby, the OBCs are supposed to be a better alternative for customers. However, OBCs have some specific limitations, since the added charger will increase the volume, weight and cost, as well as the charging time, which is too long for normal usage. Therefore, novel OBCs with low volume, high efficiency, high power density and high power capability are needed [3].

From the perspective of structure, OBCs are classified into two types: a single-stage topology and a multi-stage topology. The multi-stage (mostly two-stage) structures are commonly used at present due to their favorable features. A simplified structure of the two-stage OBC using digital signal processor (DSP) or microcontroller unit (MCU) as controller is shown in Figure 1. The two-stage structure has the advantages of a wide adjustable output voltage range and high flexibility of the output load. To satisfy the requirements of the conversion efficiency, soft switching technology is widely used in the DC/DC converter. The most commonly-used topologies are the phase shifted zero-voltage-switching (ZVS) topology [6-10] and the resonant tank with two inductors and a capacitor (LLC) resonant topology [11-13]. The shifted ZVS topology can achieve a relatively high output power level, which is more than a dozen kilowatts with an efficiency between $95 \%$ and $97 \%$. However, it also has some drawbacks, such as a limited soft switching range and being sensitive to the parasitic parameters of switch devices and the leakage inductance of the transformer. All of these problems will increase the design difficulty. The LLC resonant topology has disadvantages, such as a low power rating and a rigorous design of the transformer and inductor because of the parasitic parameters. In addition, the wide frequency range of the LLC structure increases the difficulty of the design process for the input electromagnetic interference (EMI) filter.

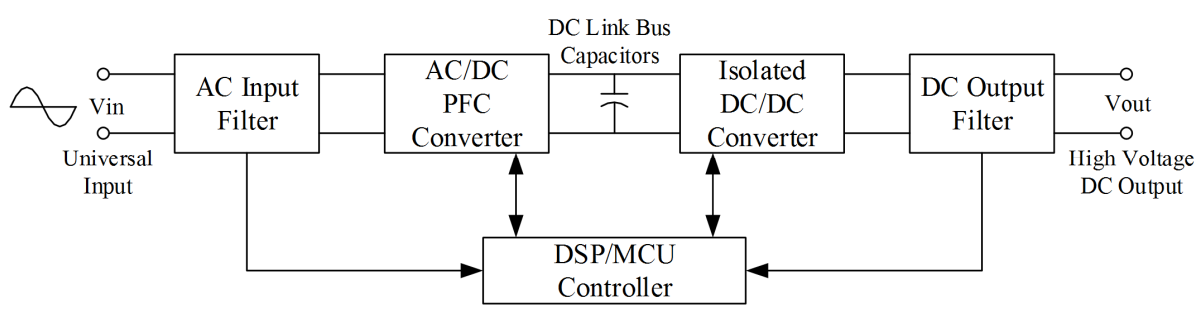

Figure 1. Simplified block diagram of a universal single-phase onboard charger (OBC); power factor correction (PFC).

Compared with the two-stage structure, the single-stage structure will reduce the number of devices and circuit complexity, so it is easier to get low volume, high efficiency and high power density. Furthermore, 
to realize rapid charging for EVs, three-phase $\mathrm{AC} / \mathrm{DC}$ converters are widely used in the single-stage charging structure.

A large number of three-phase AC-DC converters have been developed to improve power factor correction (PFC), to reduce THD and EMI of the AC input and to regulate DC output, which are addressed as the three-phase improved power quality AC-DC converters (IPQCs). Concerning topologies, these circuits can be classified into five categories: buck, boost, buck-boost, multilevel and multi-pulse [14].

The output voltage of the boost IPQCs is higher than the peak input voltage, which will result in a high output voltage or a decrease of the input voltage to satisfy the output requirement. Therefore, this kind of converter is usually used to provide a constant, regulated DC output voltage [14,15]. Furthermore, there are many problems hindering the buck-boost IPQCs from high-power applications, such as the storage capacitor selection and the reversed output voltage polarity. Therefore, the boost and buck-boost IPQCs are not suitable for the single-stage OBC application.

The buck IPQCs with high-frequency switching devices are extensively used in battery charging for automotive applications [16]. These circuits can reduce the filter size and weight and enhance the efficiency of the system. Several topologies, such as using a single switch with a diode bridge rectifier [17], three switches with a dual diode, shown in Figure 2a [18], and six switches with free-wheeling diodes, shown in Figure $2 \mathrm{~b}$ [19], are used to improve the power factor, to reduce the harmonic currents of AC input and to get a well-filtered output DC voltage.

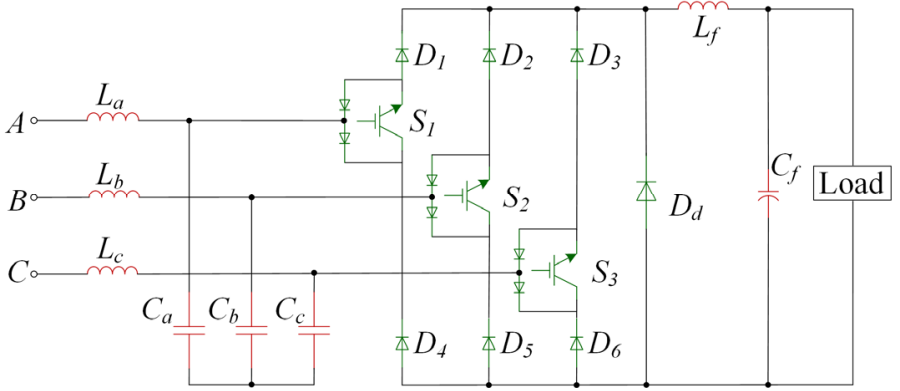

(a)

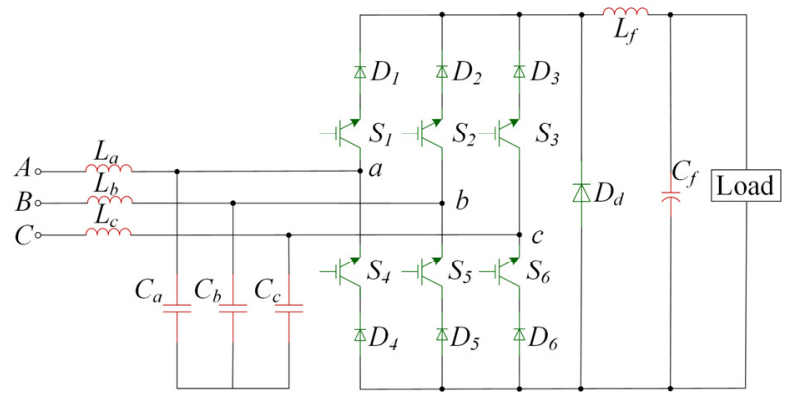

(b)

Figure 2. Three-phase AC-DC buck converters: (a) three-switch buck converter; (b) six switch with free-wheeling diode buck converter.

To enhance the efficiency and switching frequency of buck IPQCs, Robert W. Erickson and Yungtaek Jang proposed a new zero-current-switching (ZCS) three-phase high quality rectifier, which is illustrated in Figure 3 [15,20,21]. In this three-phase ZCS buck circuit, continuous input and output currents, a high power factor and low harmonic rectification are achieved. By the usage of a multi-resonant scheme, the switch operates in ZCS mode, and the diodes operate in ZVS mode; therefore, this circuit is suitable for the high-frequency implementation with insulated gate bipolar transistor (IGBT) [21]. 


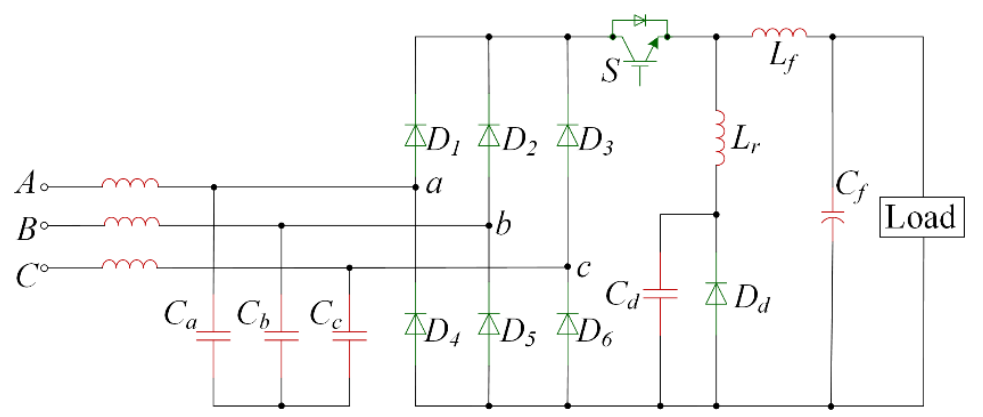

Figure 3. New three-phase multi-resonant zero-current-switching buck rectifier.

In view of the aforementioned advantages, this three-phase ZCS buck topology is adopted and optimized in this article. Although this topology can satisfy the requirement of single-stage OBC in general, the battery characteristics and the ZCS boundary condition of the multi-resonant tank, as well as their influence on each other have to be considered. Moreover, the output voltage and current fluctuations should be carefully considered for different battery statuses. Many charging strategies for EV batteries have been proposed [22-26]. Comprehensively considering the life cycle of batteries and the feasibility of the control methods, the three-stage charging strategy is selected in this article. Then, this article studies the influence between the realization of ZCS and the battery parameters or status changes and solves the problem of the large input current ripple and the useless large resonant current within the tank when the driving frequency is extremely low under light load conditions.

In addition, an interleaved structure is used to improve the power level of the OBC system in this paper, which can reduce the charging current ripple and inductor size, and it also reduces the current stress on output capacitors $[1,27,28]$. Finally, a prototype platform was built to verify the feasibility of the proposed topology. Besides, the SiC Schottky diodes were applied to promote the power level and the system efficiency $[29,30]$.

The structure of this article is organized as follows. The operating states and principles are shown in Section 2. Section 3 explains the process of the system design, the ZCS border conditions, the impact caused by the battery load and the novel PWM and PFM combined control strategy. Section 4 presents the simulation and experimental results to evaluate the proposed converter. Finally, Section 5 concludes the work carried out in this article.

\section{System Introduction}

The proposed interleaved three-phase multi-resonant ZCS OBC is shown in Figure 4. It is composed of the input filter inductors $L_{a}, L_{b}, L_{c}, L_{a s}, L_{b s}, L_{c s}$, input resonant capacitors $C_{r 1}, C_{r 2}, C_{r 3}, C_{r s 1}, C_{r s 2}, C_{r s 3}$, uncontrolled rectifier bridges $D_{1}-D_{6}$ and $D_{s 1}-D_{s 6}$, resonant inductors $L_{r}$ and $L_{r s}$, output resonant capacitors $C_{d}$ and $C_{d s}$, fly-wheel diodes $D_{d}$ and $D_{d s}$, output filter inductor $L_{f}$ and $L_{f s}$ and output filter capacitor $C_{f}$. In this topology, $C_{r 1}-C_{r}, C_{d}$ and $L_{r}$ constitute a resonant tank, and the resonance cycle of this is fixed. Therefore, the PFM control strategy with a constant turn on time is adopted, and the output voltage will increase with the driving frequency increasing while other circuit parameters remain the same. 


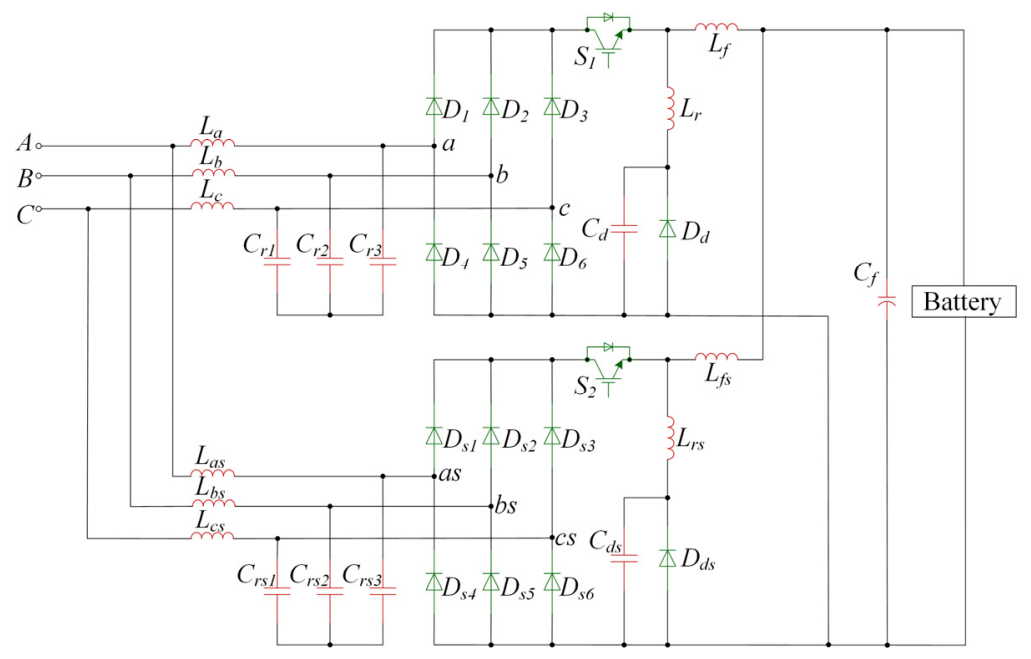

Figure 4. The proposed OBC.

Due to the structures of the two interleaved channels being completely the same, the following analysis is based on the single-channel structure. This topology is established on the basis of the three-phase single-switch rectifier [16], in which the output voltage is controllable from zero to the peak AC input line voltage. Only one IGBT in each channel needs to be controlled in this structure. In the proposed topology, $C_{r 1}-C_{r 3}, C_{d}$ and $L_{r}$ constitute a multi-resonant tank, which can guarantee the IGBTs $S_{1}$ and $S_{2}$ working in ZCS mode and diodes $D_{d}$ and $D_{d s}$ operating in ZVS mode. Moreover, by the usage of the multi-resonant scheme and the interleaved structure, this converter can improve the power level and achieve high quality input current and almost unity power factor; which can reduce the input and output side ripples and decrease the volume of the circuit.

The operating waveforms of the input side resonant capacitor $v_{c r}$ and IGBT current $i_{s}$ are shown in Figure 5. The voltage $v_{c r}$ can be divided into four parts: during $T_{1}$, IGBT is turned off, and $C_{r}$ is charged with input current; during $T_{2}, C_{r}, L_{r}$ and $C_{d}$ form a resonant tank, until $v_{c r}$ decreases to zero; $v_{c r}$ remains zero during $T_{3}$; during $T_{4}, C_{r}$ is charged with a current of input line current $i_{\text {in }}$ minus the IGBT current $i_{s}$. While the average value of $v_{c r}$ is the same as the input voltage during each switching cycle, and peak value of $v_{c r}$ is proportional to the input current. If interval $T_{1}$ is much longer than the sum of $T_{2}, T_{3}$ and $T_{4}$, the input current will follow the input voltage waveform. The details of the working process and control strategy will be analyzed below.

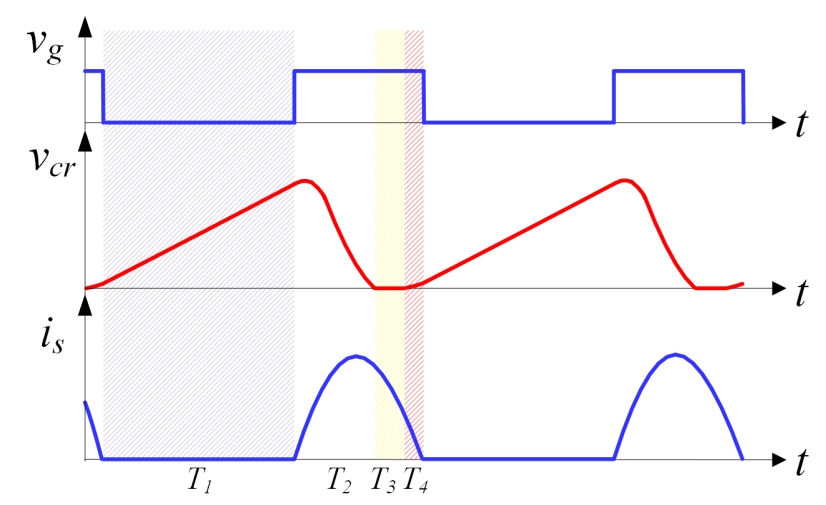

Figure 5. The waveforms of the input side capacitor voltage $v_{c r}$ and insulated gate bipolar transistor (IGBT) currentis. 


\subsection{Operating States}

Both of the interleaved channels adopt same control strategy, but hold a phase shift of $\pi$ in driving signal from each other. Assuming that the three-phase input voltages are symmetrical and balanced, it is sufficient to consider a 30-degree interval of the AC input. The 30-degree interval where $v_{a}>0>v_{c}>v_{b}$ is introduced. In order to simplify the algorithm, we choose the operating point at $\pi / 2$ to analyze the operating process of each period.

$V_{P M}$ and $I_{P M}$ represent the peak input phase voltage and current, respectively. At the point of $\pi / 2$, both $v_{A}$ and $i_{A}$ reach the peak value of the phase voltage and current, and $v_{B}=v_{C}=-0.5 v_{A}, v_{A}=V_{P M}$. Similarly, $i_{B}=i_{C}=-0.5 i_{A}, i_{A}=I P M$. At this point, the input side resonant capacitor $C_{r 2}$ and $C_{r 3}$ are charged and discharged entirely synchronously, and diodes of phase $B$ and $C$ of the uncontrolled rectifier are turned on and off synchronously, too. Therefore, the following analysis of $C_{r 3}$ is neglected.

Since the driving frequency is much higher than the input voltage frequency, so during one switching cycle the input voltage and current can be considered as a constant value. The ideal operating waveforms of the OBC is shown in Figure 6, and the equivalent circuits of each interval are shown in Figure 7.

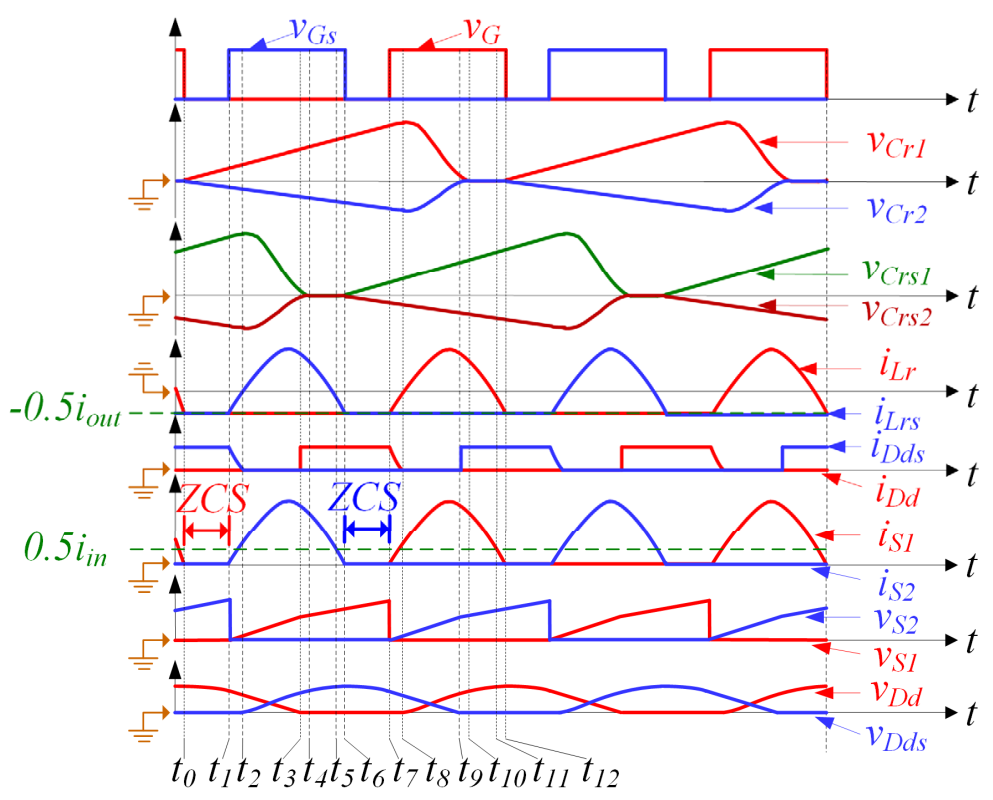

Figure 6. Ideal waveforms of the charger mode.

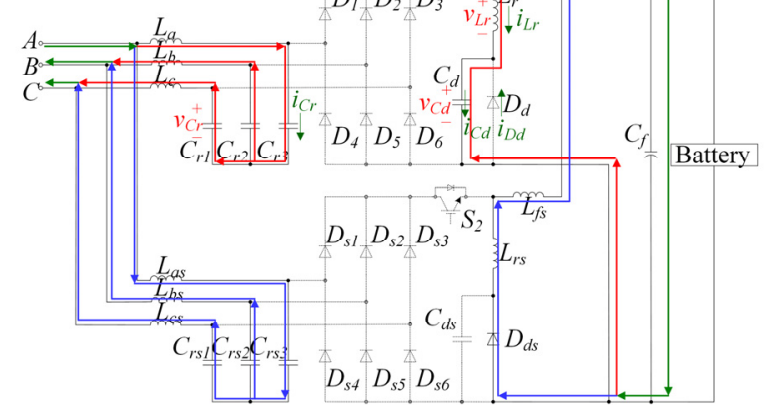

(a)

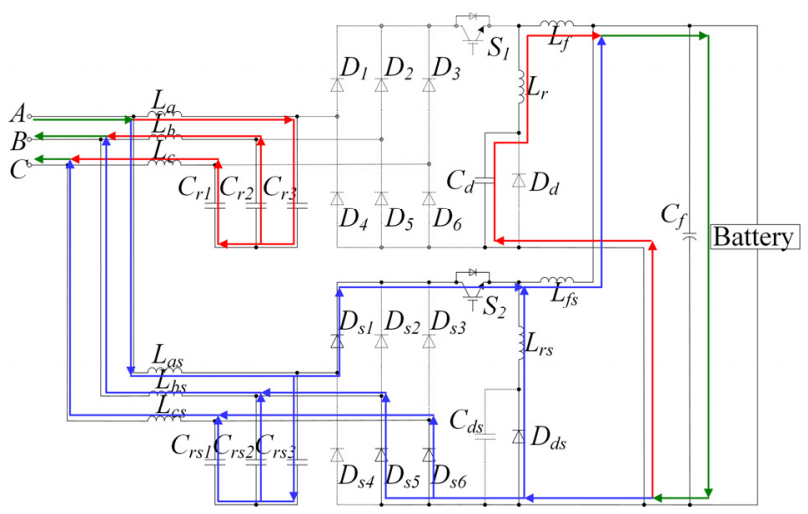

(b)

Figure 7. Cont. 


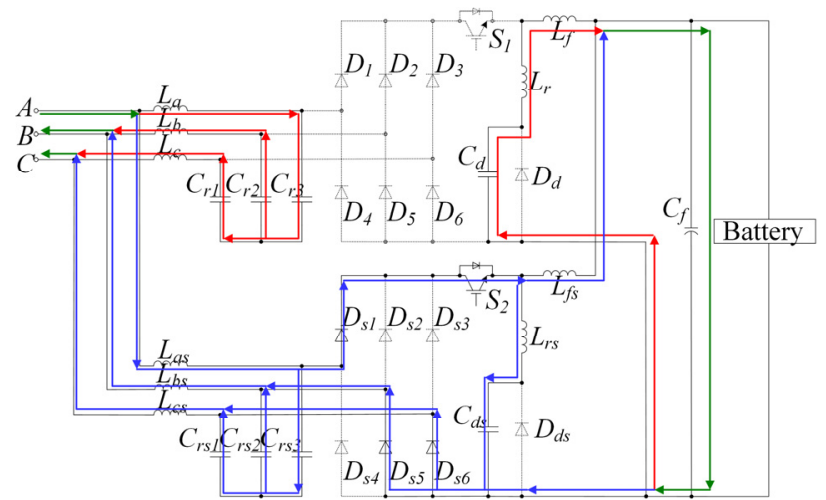

(c)

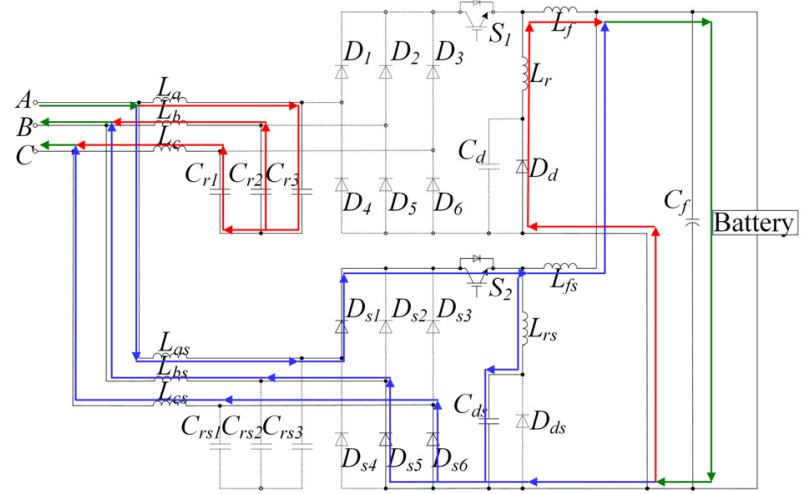

(e)

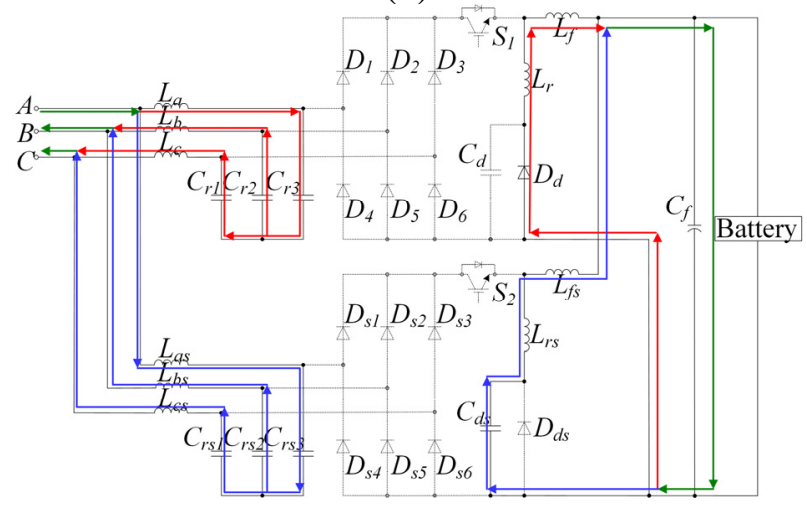

(g)

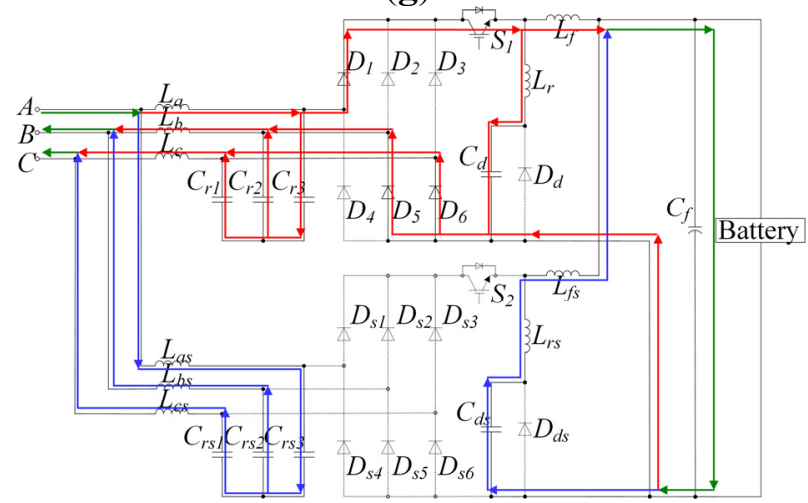

(i)

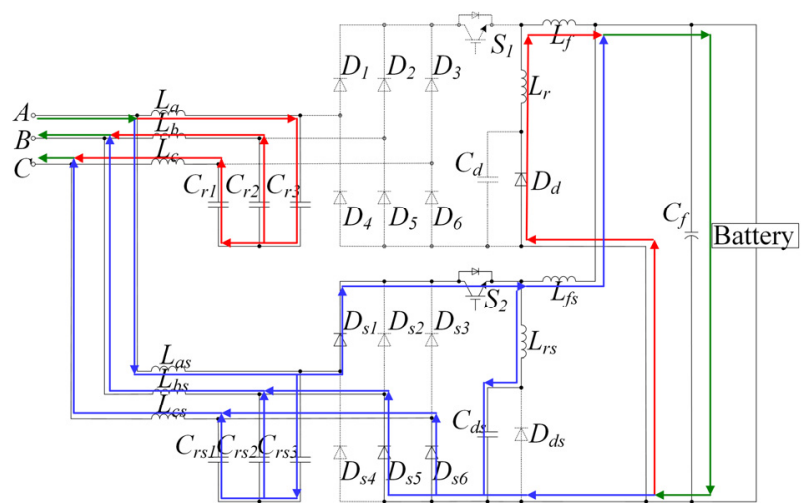

(d)

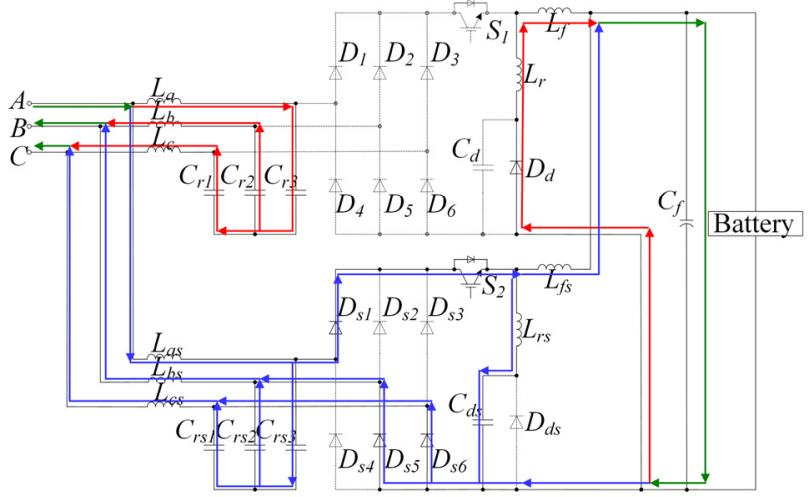

(f)

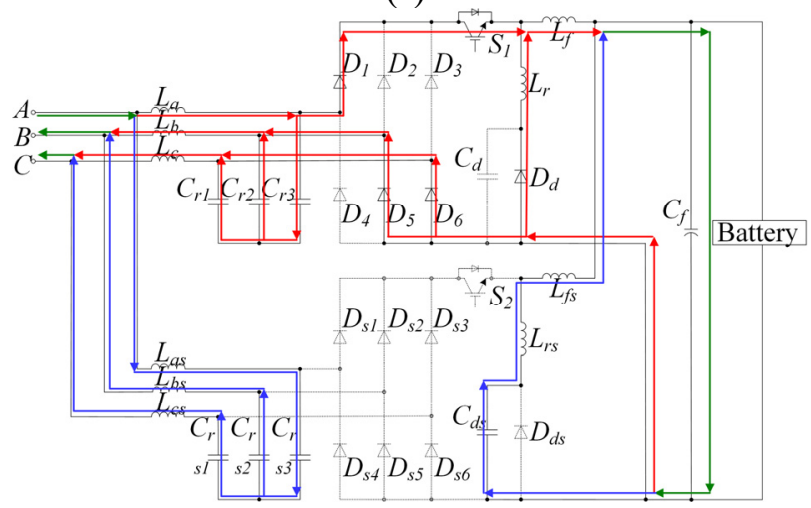

(h)

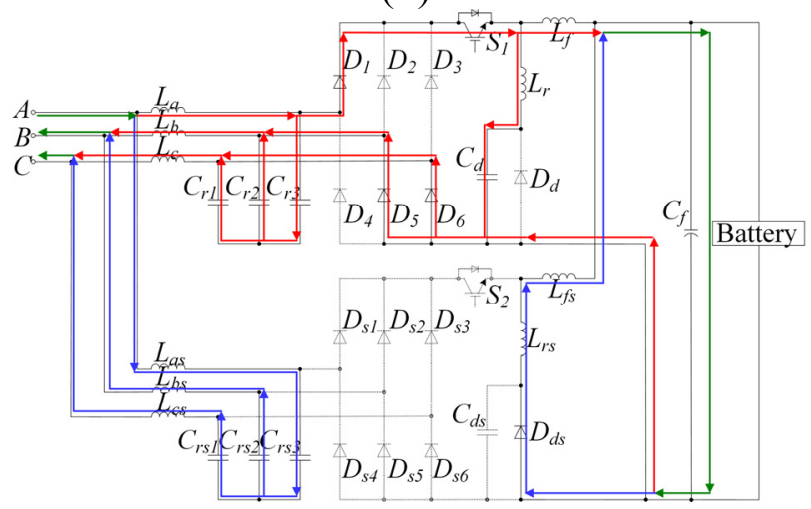

(j)

Figure 7. Cont. 


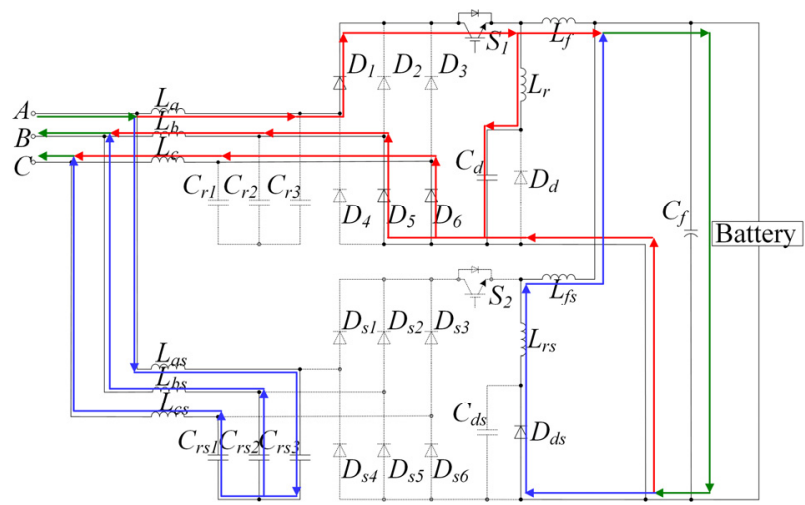

$(\mathbf{k})$

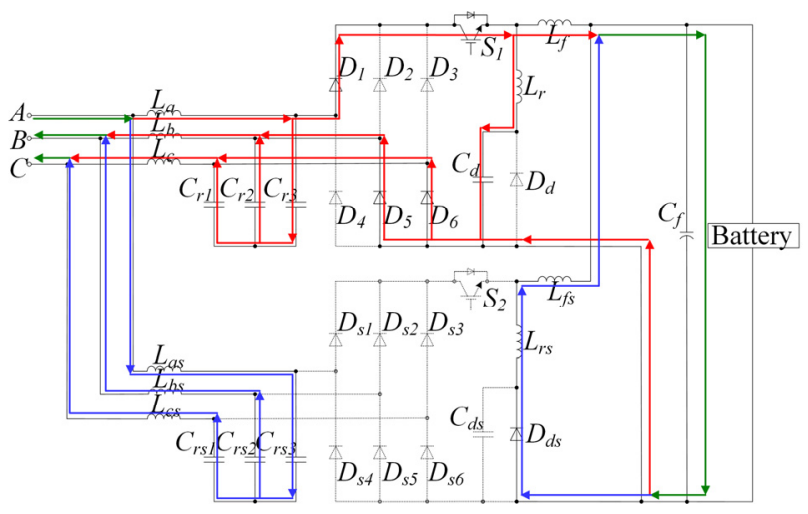

(l)

Figure 7. Equivalent circuits of each interval. (a) $t_{0}-t_{1}$; (b) $t_{1}-t_{2}$; (c) $t_{2}-t_{3} ;$ (d) $t_{3}-t_{4} ;$ (e) $t_{4}-t_{5}$; (f) $t_{5}-t_{6} ;$ (g) $t_{6}-t_{7} ;$ (h) $t_{7}-t_{8} ;(\mathbf{i}) t_{8}-t_{9} ;(\mathbf{j}) t_{9}-t_{10} ;$ (k) $t_{10}-t_{11} ;$ (l) $t_{11}-t_{12}$.

The parameters are defined as follows: $v_{C r 1}-v_{C r} 3$ and $i_{C r 1}-i_{C r} 3$ are the voltage and current of resonant capacitors $C_{r 1}-C_{r 3}$, respectively; $v_{C d}$ and $i_{C d}$ are the voltage and current of the resonant capacitor $C_{d}$, respectively; $v_{L r}$ and $i_{L r}$ are the voltage and current of the resonant inductor $L_{r}$, respectively; $I_{o u t}$ is the output current; $V_{\text {out }}$ is the output voltage; $i_{C f}$ is the current of $C_{f}$. Since the two paralleled channels use the same control strategy, the single channel will be introduced in the following theoretical analysis and calculation parts. The input and output current for each channel are the half of the total circuit and can be defined as $0.5 I_{P M}$ and $0.5 I_{\text {out }}$. The capacitance values of $C_{r 1}-C_{r 3}$ are the same and can be represented as $C_{r}$. Figure 7a illustrates the voltage and current reference directions of the devices for the following analysis, and the reference directions of $C_{r 1}-C_{r 3}$ are exactly the same.

Interval I $\left(t_{0}-t_{3}\right): D_{1}-D_{6}, S_{1}$ and $D_{d}$ are off. $C_{r 1}-C_{r 3}$ are charged by the input current. During this interval, $L_{r}$ provides the output current. $C_{d}$ is discharged with $i_{L r}$, and $C_{f}$ is also charged. This interval ends when $v_{C d}$ decreases to zero and $D_{d}$ is turned on. The state equations of this interval are:

$$
\left\{\begin{array}{l}
C_{r} \frac{\mathrm{d} v_{C r 1}(t)}{\mathrm{d} t}=0.5 I_{P M} \\
C_{r} \frac{\mathrm{d} v_{C r 2}(t)}{\mathrm{d} t}=-0.25 I_{P M} \\
C_{d} \frac{\mathrm{d} v_{C d}(t)}{\mathrm{d} t}=i_{C d}(t) \\
V_{L f}(t)=L_{f} \frac{\mathrm{d} i_{L f}(t)}{\mathrm{d} t} \\
i_{C d}(t)=i_{L r}(t)=-i_{L f}(t)=-0.5 I_{\text {out }}+i(t) \\
v_{C d}(t)+v_{L r}(t)=v_{L f}(t)+V_{\text {out }} \\
v_{s}(t)+v_{C d}(t)=v_{C r 1}(t)-v_{C r 2}(t)
\end{array}\right.
$$

In Equation (1), $i(t)$ represents the fluctuation component of the freewheel current through $C_{d}, L_{r}$ and $L f$. From the perspective of the current analysis, $i(t)$ can be ignored, while in the voltage analysis, $i(t)$ will cause a decided change of $V_{L f}(t)$. Moreover, $V_{L r}(t)$ can be considered as a constant value in this interval, in view of the fact that compared to $L_{f}$, the value of $L_{r}$ is very small.

Interval II $\left(t_{3} \sim t_{7}\right): D_{d}$ is on, and $D_{1} \sim D_{6}$ and $S_{1}$ are off. The output current is still supplied by $L_{r}$. The only difference between Interval I and Interval II is that the current flows through $D_{d}$, rather than 
the resonant capacitor $C_{d}$. This interval ends when the switch $S_{1}$ is turned on. The state equations of this interval are:

$$
\left\{\begin{array}{l}
C_{r} \frac{\mathrm{d} v_{C r 1}(t)}{\mathrm{d} t}=0.5 I_{P M} \\
C_{r} \frac{\mathrm{d} v_{C r 2}(t)}{\mathrm{d} t}=-0.25 I_{P M} \\
i_{L r}(t)=-i_{D d}(t)=-i_{L f}(t)=-0.5 I_{\text {out }}+i(t) \\
v_{s}(t)=v_{C r 1}(t)-v_{C r 2}(t)
\end{array}\right.
$$

Interval III ( $\left.t_{7}-t_{8}\right): D_{1}, D_{5}, D_{6}, S_{1}$ and $D_{d}$ are on, and the other diodes are off. $C_{r 1}-C_{r 3}$ and $L_{r}$ form a resonant tank, until the inductor current increases to zero. The state equations of this interval are:

$$
\left\{\begin{array}{l}
C_{r} \frac{\mathrm{d} v_{C r 1}(t)}{\mathrm{d} t}=i_{C r 1}(t) \\
C_{r} \frac{\mathrm{d} v_{C r 2}(t)}{\mathrm{d} t}=i_{C r 2}(t) \\
L_{r} \frac{\mathrm{d} i_{L r}(t)}{\mathrm{d} t}=v_{L r}(t) \\
i_{C r 1}(t)=-2 i_{C r 2}(t) \\
i_{S}(t)=i_{L f}(t)+i_{L r}(t) \\
v_{L r}(t)=v_{C r 1}(t)-v_{C r 2}(t) \\
i_{C r 1}(t)+i_{S}(t)=0.5 I_{P M}
\end{array}\right.
$$

Interval IV (ts $\left.-t_{10}\right): D_{1}, D_{5}, D_{6}$ and $S_{1}$ are on, and $D_{2}-D_{4}$ and $D_{d}$ are off. $C_{d}, C_{r}$ and $L_{r}$ form a resonant tank. This interval ends until the voltage of $C_{r}$ decreases to zero. The state equations of this interval are:

$$
\left\{\begin{array}{l}
C_{r} \frac{\mathrm{d} v_{C r 1}(t)}{\mathrm{d} t}=i_{C r 1}(t) \\
C_{r} \frac{\mathrm{d} v_{C r 2}(t)}{\mathrm{d} t}=i_{C r 2}(t) \\
i_{C r 1}(t)=-2 i_{C r 2}(t) \\
i_{S}(t)=i_{L f}(t)+i_{L r}(t) \\
L_{r} \frac{\mathrm{d} i_{L r}(t)}{\mathrm{d} t}+v_{C d}(t)=L_{f} \frac{\mathrm{d} i_{L f}(t)}{\mathrm{d} t}+V_{\text {out }}=v_{C r 1}(t)-v_{C r 2}(t) \\
0.5 I_{P M}=i_{C r 1}(t)+i_{S}(t)
\end{array}\right.
$$

Interval V (t $\left.t_{10}-t_{11}\right): D_{1}-D_{6}$ and $S_{1}$ are on, and $D_{d}$ is off. $L_{r}$ and $C_{d}$ form a resonant tank. This interval ends when the current $i_{S 1}$ reduces to the input current $0.5 I_{P M}$. If $i_{S 1}<0.5 I_{P M}$, then the current $i_{C r 1}>0$, and the input capacitor begins to charge, indicating that this interval ends. The state equations of this interval are:

$$
\left\{\begin{array}{l}
L_{r} \frac{\mathrm{d} i_{L r}(t)}{\mathrm{d} t}+v_{C d}(t)=0 \\
C_{d} \frac{\mathrm{d} v_{C d}(t)}{\mathrm{d} t}=i_{C d}(t)=i_{L r}(t) \\
i_{S}(t)=i_{L f}(t)+i_{L r}(t) \\
L_{f} \frac{\mathrm{d} i_{L f}(t)}{\mathrm{d} t}+V_{\text {out }}=0
\end{array}\right.
$$


Interval VI ( $\left.t_{11}-t_{12}\right): D_{1}, D_{5}, D_{6}$ and $S_{1}$ are on, and $D_{2}-D_{4}$ and $D_{d}$ are off. $C_{r}, C_{d}$ and $L_{r}$ form a resonant tank. This interval ends when the current $i s 1$ decreases to zero. After this ending point, $S_{1}$ can realize turning on of ZCS. The state equations of this interval are:

$$
\left\{\begin{array}{l}
C_{r} \frac{\mathrm{d} v_{C r 1}(t)}{\mathrm{d} t}=i_{C r 1}(t) \\
C_{r} \frac{\mathrm{d} v_{C r 2}(t)}{\mathrm{d} t}=i_{C r 2}(t) \\
i_{C r 1}(t)=-2 i_{C r 2}(t) \\
i_{S}(t)=i_{L f}(t)+i_{L r}(t) \\
L_{r} \frac{\mathrm{d} i_{L r}(t)}{\mathrm{d} t}+v_{C d}(t)=v_{C r 1}(t)-v_{C r 2}(t) \\
0.5 I_{P M}=i_{C r 1}(t)+i_{S}(t)
\end{array}\right.
$$

\subsection{Operating Analysis}

This section will carry out a further analysis of the operating principle during each interval. From the state Equations (1)-(6), the current and voltage expressions of $S_{1}, L_{r}, C_{r}$ and $C_{d}$ can be calculated. Then, the starting and ending point of each interval are confirmed, which will be used to determine the ZCS boundary and to provide the basis for the circuit design.

By solving Equation (1), the expressions of the main power devices of Interval I are listed as:

$$
\left\{\begin{array}{l}
v_{C r 1}(t)=\frac{I_{P M}}{2 C_{r}} t \\
v_{C r 2}(t)=v_{C r 3}(t)=-\frac{I_{P M}}{4 C_{r}} t \\
v_{C d}(t)=\left.V_{C d}\right|_{T 0}-\frac{I_{\text {out }}}{2 C_{d}} t \\
i_{L f}(t)=\frac{I_{\text {out }}}{2}+\frac{\left.V_{C d}\right|_{T 0}-V_{\text {out }}}{L_{f}} t-\frac{I_{\text {out }}}{4 L_{f} C_{d}} t^{2}+C_{11} \\
i_{C d}(t)=i_{L r}(t)=-i_{L f}(t) \\
v_{L f}(t)=\left.V_{C d}\right|_{T 0}-V_{\text {out }}-\frac{I_{\text {out }}}{2 L_{f} C_{d}} t \\
v_{S}(t)=\frac{3 I_{P M}}{4 C_{r}} t-\left.V_{C d}\right|_{T 0}+\frac{I_{\text {out }}}{2 C_{d}} t
\end{array}\right.
$$

As analyzed above, Interval I will end when $v_{C d}$ decreases to zero, so the ending moment $T_{1}$ and $C_{11}$ can be deduced as:

$$
\begin{gathered}
T_{1}=\frac{\left.2 V_{C d}\right|_{T 0} C_{d}}{I_{o u t}} \\
C_{11}=\left.I_{L f}\right|_{T 0}-\frac{I_{\text {out }}}{2}
\end{gathered}
$$

Then, the value of each electric parameter at the ending time of Interval I can be derived as: 


$$
\left\{\begin{array}{l}
\left.V_{C d}\right|_{T_{1}}=0 \\
\left.V_{C r 1}\right|_{T_{1}}=\frac{\left.I_{P M} V_{C d}\right|_{T 0} C_{d}}{I_{\text {out }} C_{r}} \\
\left.V_{C r 2}\right|_{T_{1}}=\left.V_{C r 3}\right|_{T_{1}}=-\frac{\left.I_{P M} V_{C d}\right|_{T 0} C_{d}}{2 I_{\text {out }} C_{r}} \\
\left.V_{S}\right|_{T_{1}}=\frac{\left.3 I_{P M} V_{C d}\right|_{T 0} C_{d}}{2 I_{\text {out }} C_{r}} \\
\left.I_{L f}\right|_{T_{1}}=\frac{I_{\text {out }}}{4}+\frac{\left.V_{C d}\right|_{T 0}-V_{\text {out }}}{L_{f}} \frac{\left.V_{C d}\right|_{T 0} C_{d}}{I_{\text {out }}}-\frac{2 I_{\text {out }}}{L_{f} C_{d}}\left(\frac{\left.V_{C d}\right|_{T 0} C_{d}}{I_{\text {out }}}\right)^{2}+C_{11} \\
\left.I_{C d}\right|_{T_{1}}=\left.I_{L r}\right|_{T_{1}}=-\left.I_{L f}\right|_{T_{1}} \\
\left.V_{L f}\right|_{T_{1}}=-V_{\text {out }}
\end{array}\right.
$$

Similarly, by solving Equations (2)-(6), the expressions of Intervals II-VI can be obtained.

For Interval II, the expressions of the main devices of can be listed as:

$$
\left\{\begin{array}{l}
v_{C r 1}(t)=\frac{I_{P M}}{2 C_{r}}\left(t+T_{1}\right) \\
v_{C r 2}(t)=v_{C r 3}(t)=-\frac{V_{C r 1}(t)}{2} \\
v_{S}(t)=\frac{3 v_{C r 1}(t)}{2} \\
v_{L f}(t)=-V_{\text {out }} \\
i_{L f}(t)=\frac{I_{\text {out }}}{2}-\frac{V_{\text {out }}}{L_{f}} t+C_{21} \\
i_{D d}(t)=i_{L f}(t)=-i_{L r}(t)
\end{array}\right.
$$

For the duration of Interval II, $T_{2}$ and the final value of each electric parameter can be inferred as:

$$
\begin{gathered}
T_{2}=D T_{s}-T_{1} \\
C_{21}=\left.I_{L f}\right|_{T 1}-\frac{I_{\text {out }}}{2} \\
\left\{\begin{array}{l}
\left.V_{C r 1}\right|_{T_{2}}=\frac{I_{P M} D T_{S}}{2 C_{r 1}} \\
\left.V_{C r 2}\right|_{T_{2}}=\left.V_{C r 3}\right|_{T_{2}}=-\frac{I_{P M} D T_{S}}{4 C_{r 1}} \\
\left.V_{S}\right|_{T_{2}}=\frac{3 I_{P M} D T_{S}}{4 C_{r 1}} \\
\left.I_{L f}\right|_{T_{2}}=\left.I_{L f}\right|_{T_{2}}-\frac{V_{\text {out }}}{L_{f}}\left(D T_{S}-T_{1}\right) \\
\left.I_{D d}\right|_{T_{2}}=\left.I_{L f}\right|_{T_{2}}=-\left.I_{L r}\right|_{T_{2}}
\end{array}\right.
\end{gathered}
$$

For Interval III, the expressions of the main devices can be listed as: 


$$
\left\{\begin{array}{l}
v_{C r 1}(t)=C_{31} \sin \alpha_{3} t+C_{32} \cos \alpha_{3} t \\
i_{C r 1}(t)=C_{31} C_{r} \alpha_{3} \cos \alpha_{3} t-C_{32} C_{r} \alpha_{3} \sin \alpha_{3} t \\
i_{S}(t)=\frac{I_{P M}}{2}-C_{31} C_{r} \alpha_{3} \cos \alpha_{3} t+C_{32} C_{r} \alpha_{3} \sin \alpha_{3} t \\
i_{L r}(t)=\frac{I_{P M}}{2}-\frac{I_{\text {out }}}{2}-C_{31} C_{r} \alpha_{3} \cos \alpha_{3} t+C_{32} C_{r} \alpha_{3} \sin \alpha_{3} t \\
v_{L r}(t)=L_{r} C_{31} C_{r} \alpha_{3}^{2} \sin \alpha_{3} t+L_{r} C_{32} C_{r} \alpha_{3}^{2} \cos \alpha_{3} t
\end{array}\right.
$$

By substituting the final value of Interval II into Equation (15), the parameters can be shown as:

$$
\begin{gathered}
\alpha_{3}=\sqrt{\frac{3}{2 L_{r} C_{r}}} \\
\left\{\begin{array}{l}
C_{31}=\frac{\left.I_{C r 1}\right|_{T 2}}{C_{r} \alpha_{3}} \\
C_{32}=\left.V_{C r 1}\right|_{T 2}
\end{array}\right.
\end{gathered}
$$

For the duration of Interval III, $T_{3}$ and the final value of each parameter can be deduced as:

$$
\begin{aligned}
& T_{3}=\arcsin \left[M_{3}\right] \\
& M_{3}=\frac{\left(\frac{I_{\text {out }}}{2}-\frac{I_{g}}{2}\right) C_{32} C_{r} \alpha_{3}+\sqrt{-\left(\frac{I_{\text {out }}}{2}-\frac{I_{g}}{2}\right)^{2} C_{31}{ }^{2} C_{r}{ }^{2} \alpha_{3}{ }^{2}+C_{31}{ }^{4} C_{r}{ }^{4} \alpha_{3}{ }^{4}+C_{31}{ }^{2} C_{32}{ }^{2} C_{r}^{4} \alpha_{3}{ }^{4}}}{C_{r}{ }^{2} \alpha_{3}{ }^{2}\left(C_{31}{ }^{2}+C_{32}{ }^{2}\right)} \\
& N_{3}=\sqrt{1-M_{3}^{2}} \\
& \left\{\begin{array}{l}
\left.V_{C r 1}\right|_{T 3}=C_{31} M_{3}+C_{32} N_{3} \\
\left.I_{C r 1}\right|_{T 3}=C_{31} C_{r} \alpha_{3} N_{3}-C_{32} C_{r} \alpha_{3} M_{3}=\frac{I_{P M}}{2}-C_{31} C_{r} \alpha_{3} N_{3}+C_{32} C_{r} \alpha_{3} M_{3} \\
\left.I_{L r}\right|_{T 3}=\frac{I_{P M}}{2}-\frac{I_{\text {out }}}{2}-C_{31} C_{r} \alpha_{3} N_{3}+C_{32} C_{r} \alpha_{3} M_{3} \\
\left.V_{L r}\right|_{T 3}=L_{r} C_{31} C_{r} \alpha_{3}{ }^{2} M_{3}+L_{r} C_{32} C_{r} \alpha_{3}{ }^{2} N_{3}
\end{array}\right.
\end{aligned}
$$

For Interval IV, the voltage and current expressions of the main devices can also be deduced by solving Equation (4). They can be listed as:

$$
\left\{\begin{array}{l}
i_{L r}(t)=C_{41} \sin \alpha_{4} t \\
i_{C d}(t)=C_{41} \sin \alpha_{4} t \\
v_{L r}(t)=C_{41} L_{r} \alpha_{4} \cos \alpha_{4} t \\
v_{C d}(t)=\frac{C_{41}}{C_{d} \alpha_{4}}\left(1-\cos \alpha_{4} t\right) \\
v_{C r 1}(t)=\frac{2}{3}\left[C_{41} L_{r} \alpha_{4} \cos \alpha_{4} t+\frac{C_{41}}{C_{d} \alpha_{4}}\left(1-\cos \alpha_{4} t\right)\right] \\
i_{C r 1}(t)=\left(\frac{2 C_{41} C_{r 1}-2 C_{41} C_{r 1} L_{r} C_{d} \alpha_{4}{ }^{2}}{3 C_{d}}\right) \sin \alpha_{4} t \\
i_{S}(t)=\frac{I_{P M}}{2}-\left(\frac{2 C_{41} C_{r 1}-2 C_{41} C_{r 1} L_{r} C_{d} \alpha_{4}{ }^{2}}{3 C_{d}}\right) \sin \alpha_{4} t \\
i_{L f}(t)=\frac{I_{P M}}{2}-\left(\frac{2 C_{41} C_{r 1}-2 C_{41} C_{r 1} L_{r} C_{d} \alpha_{4}{ }^{2}-3 C_{41} C_{d}}{3 C_{d}}\right) \sin \alpha_{4} t
\end{array}\right.
$$


The parameters of Equation (20) can be determined by the final value of Interval III.

$$
\begin{gathered}
\alpha_{4}=\sqrt{\frac{L_{r}+2 L_{f}+\sqrt{4 L_{f}^{2}+L_{r}^{2}}}{2 C_{d} L_{f} L_{r}}} \\
C_{41}=\frac{\left.V_{L r}\right|_{T 3}}{L_{r} \alpha_{4}}
\end{gathered}
$$

For the duration of Interval IV, $T_{4}$ and the final value of each electric parameter can be derived as:

$$
\begin{aligned}
& T_{4}=\frac{\arccos \left[N_{4}\right]}{\alpha_{4}} \\
& N_{4}=\frac{1}{1-L_{r} C_{d} \alpha_{4}^{2}} \\
& M_{4}=\sqrt{1-N_{4}^{2}}
\end{aligned}
$$

For Interval V, according to the above operating states' analysis, we can deduce the expressions of the electrical parameters as:

$$
\left\{\begin{array}{l}
i_{L r}(t)=C_{51} \sin \alpha_{5} t+C_{52} \cos \alpha_{5} t \\
v_{C d}(t)=C_{51} L_{r} \alpha_{5} \cos \alpha_{5} t-C_{52} L_{r} \alpha_{5} \sin \alpha_{5} t \\
i_{L r}(t)=i_{C d}(t) \\
i_{L f}(t)=-\frac{V_{\text {out }}}{L_{f}} t+C_{53} \\
v_{L r}(t)=C_{52} L_{r} \alpha_{5} \sin \alpha_{5} t-C_{51} L_{r} \alpha_{5} \cos \alpha_{5} t \\
i_{S}(t)=C_{51} \sin \alpha_{5} t+C_{52} \cos \alpha_{5} t-\frac{V_{\text {out }}}{L_{f}} t+C_{53}
\end{array}\right.
$$

The parameters in Equation (25) are listed as:

$$
\alpha_{5}=\frac{1}{\sqrt{L_{r} C_{d}}}
$$




$$
\left\{\begin{array}{l}
C_{51}=\left.\mathrm{V}_{C d}\right|_{T 4} \\
C_{52}=\frac{\left.\mathrm{I}_{C d}\right|_{T 4}}{C_{d} \alpha_{5}} \\
C_{53}=\left.\mathrm{I}_{L f}\right|_{T 4}
\end{array}\right.
$$

Since this interval ends when $i_{S 1}$ reduces to $0.5 I_{P M}$ and from Equations (25)-(27), the time length of this interval $T_{5}$ can be deduced as:

$$
\begin{aligned}
& T_{5}=\arcsin \left[M_{5}\right] \\
& M_{5}=\frac{C_{51}\left(\frac{I_{P M}}{2}-\frac{I_{\text {out }}}{2}\right)+\sqrt{C_{51}{ }^{2} C_{52}{ }^{2}+C_{52}{ }^{4}-C_{52}{ }^{2}\left(\frac{I_{\text {out }}}{2}-\frac{I_{P M}}{2}\right)^{2}}}{\left(C_{51}{ }^{2}+C_{52}{ }^{2}\right)} \\
& N_{5}=\sqrt{1-M_{5}{ }^{2}}
\end{aligned}
$$

Then, we can get the final value of each electric parameter as:

$$
\left\{\begin{array}{l}
\left.I_{L r}\right|_{T 5}=C_{51} M_{5}+C_{52} N_{5} \\
\left.V_{C d}\right|_{T 5}=C_{51} L_{r} \alpha_{5} N_{5}-C_{52} L_{r} \alpha_{5} M_{5} \\
\left.I_{C d}\right|_{T 5}=C_{51} M_{5}+C_{52} N_{5} \\
\left.I_{L f}\right|_{T 5}=-\frac{V_{o u t}}{L_{f}} T_{5}+\left.I_{L f}\right|_{T 4} \\
\left.V_{L r}\right|_{T 5}=C_{52} L_{r} \alpha_{5} M_{5}-C_{51} L_{r} \alpha_{5} N_{5} \\
\left.I_{S}\right|_{T 5}=C_{51} M_{5}+C_{52} N_{5}-\frac{V_{\text {out }}}{L_{f}} T_{5}+\left.I_{L f}\right|_{T 4}
\end{array}\right.
$$

For Interval VI, we can deduce the expressions of the electrical parameters as:

$$
\left\{\begin{array}{l}
\left\{\begin{array}{l}
i_{C r 1}(t)=C_{61} \alpha_{6} t \\
v_{C r 1}(t)=\frac{C_{61} \alpha_{6}}{2 C_{r 1}} t^{2} \\
i_{L f}(t)=\frac{C_{61} \alpha_{6}}{6 L_{f} C_{d}} t^{3}-V_{\text {out }} t+C_{62} \\
i_{S}(t)=\frac{I_{P M}}{2}-C_{61} \alpha_{6} t \\
i_{L r}(t)=i_{C d}(t)=\frac{I_{P M}}{2}-\frac{C_{61} \alpha_{6}}{6 L_{f} C_{d}} t^{3}+V_{\text {out }} t-C_{61} \alpha_{6} t-C_{62} \\
v_{L r}(t)=L_{r}\left(V_{\text {out }}-C_{61} \alpha_{6}-\frac{C_{61} \alpha_{6}}{2 L_{f} C_{d}} t^{2}\right) \\
v_{C d}(t)=\frac{C_{61} \alpha_{6}}{2 C_{d}} t^{2}-L_{r}\left(V_{\text {out }}-C_{61} \alpha_{6}-\frac{C_{61} \alpha_{6}}{3 L_{f} C_{d}} t^{2}\right) \\
\alpha_{6}=\sqrt{\frac{L_{r}+2 L_{f}+\sqrt{4 L_{f}^{2}+L_{r}^{2}}}{2 C_{d} L_{f} L_{r}}} \\
\left\{\begin{array}{l}
C_{61}=-\frac{\left.V_{L r}\right|_{T 5}}{L_{r} \alpha_{6}} \\
C_{62}=\left.I_{L f}\right|_{T 5}
\end{array}\right.
\end{array}\right.
\end{array}\right.
$$

From Equations (30)-(32), the time length of this interval $T_{6}$ is: 


$$
T_{6}=\frac{I_{P M}}{2 C_{61} \alpha_{6}}
$$

Then, we can get the final value of each parameter as:

$$
\left\{\begin{array}{l}
\left.I_{C r 1}\right|_{T 6}=\frac{I_{P M}}{2} \\
\left.V_{C r 1}\right|_{T 6}=\frac{C_{61} \alpha_{6}}{2 C_{r 1}} t^{2} \\
\left.I_{L f}\right|_{T 6}=\frac{C_{61} \alpha_{6}}{6 L_{f} C_{d}} T_{6}^{3}-V_{\text {out }} T_{6}+C_{62} \\
\left.I_{S}\right|_{T 6}=0 \\
\left.I_{L r}\right|_{T 6}=\left.I_{C d}\right|_{T 6}=\frac{I_{P M}}{2}-\frac{C_{61} \alpha_{6}}{6 L_{f} C_{d}} T_{6}^{3}+V_{\text {out }} T_{6}-C_{61} \alpha_{6} T_{6}-C_{62} \\
\left.V_{L r}\right|_{T 6}=L_{r}\left(V_{\text {out }}-C_{61} \alpha_{6}-\frac{C_{61} \alpha_{6}}{2 L_{f} C_{d}} T_{6}^{2}\right) \\
\left.V_{C d}\right|_{T 6}=\frac{C_{61} \alpha_{6}}{2 C_{d}} T_{6}^{2}-L_{r}\left(V_{\text {out }}-C_{61} \alpha_{6}-\frac{C_{61} \alpha_{6}}{3 L_{f} C_{d}} T_{6}^{2}\right)
\end{array}\right.
$$

\section{System Design}

In this section, based on the analysis above and the battery charging requirements, the hardware parameters and control strategy are designed. The design mainly focuses on the ZCS realization when considering the differences of battery parameters and charging conditions.

\subsection{ZCS Condition Analysis}

The system cannot realize ZCS under two conditions, which are:

(1) The circuit parameters do not satisfy the ZCS requirement.

(2) The circuit parameters are appropriate, but the driving signal is mismatched.

\subsubsection{Mismatch of Circuit Parameters}

To realize ZCS, the previous stage should provide the conditions to obtain the next stage. From the ideal waveforms in Figure 6 and the operating analysis above, we can deduce the constraint expressions.

Interval I and II should be long enough to guarantee energy storage, for the resonant inductor current to be positive. This can be expressed as, at the end of Interval III, the voltage of $v_{C r}$ is positive.

$$
\left.V_{C r 1}\right|_{T 3}=C_{31} M_{3}+C_{32} N_{3}>0
$$

$C_{r}$ must be completely discharged when the resonant inductor current is positive. This can be expressed as:

$$
\left.I_{L \mathrm{r}}\right|_{T 4}=C_{41} M_{4}>0
$$

During Interval V and Interval VI, $L_{r}$ and $C_{d}$ form a resonant tank. Only if $C_{d}$ have enough energy, the resonant inductor current can reach output current $0.5 I_{\text {out }}$, and $i_{S}$ can reach zero to realize ZCS. It can be described as: 


$$
\begin{gathered}
\left.V_{C d}\right|_{T 5}=C_{51} L_{r} \alpha_{5} N_{5}-C_{52} L_{r} \alpha_{5} M_{5}>0 \\
\left.V_{C d}\right|_{T 6}=\frac{C_{61} \alpha_{6}}{2 C_{d}} T_{6}^{2}-L_{r}\left(V_{\text {out }}-C_{61} \alpha_{6}-\frac{C_{61} \alpha_{6}}{3 L_{f} C_{d}} T_{6}^{2}\right)>0
\end{gathered}
$$

Figure 8 shows the working waveforms with mismatched circuit parameters, where the converter cannot realize ZCS. We can see that the output side resonant capacitor is entirely discharged before is decreases to zero. Thus, $i_{S}$ fails to drop down to zero, and ZCS cannot be realized.

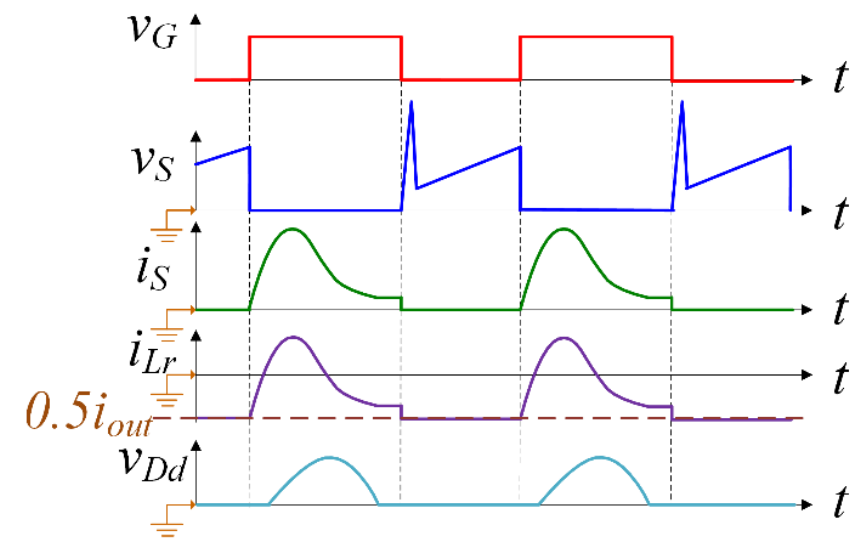

Figure 8. Typical waveforms with mismatch circuit parameters.

\subsubsection{Mismatch of the Driving Signal}

ZCS can only be realized when the circuit and the driving signal are matched. The condition that optimizes the circuit parameters with an improper driving signal is discussed below, and the typical waveforms are shown in Figure 9. Figure 9a shows the waveforms when $T_{\text {on }}$ is shorter than the minimum allowable value, and Figure $9 \mathrm{~b}$ shows the waveforms when $T_{o n}$ is longer than the maximum allowable value.

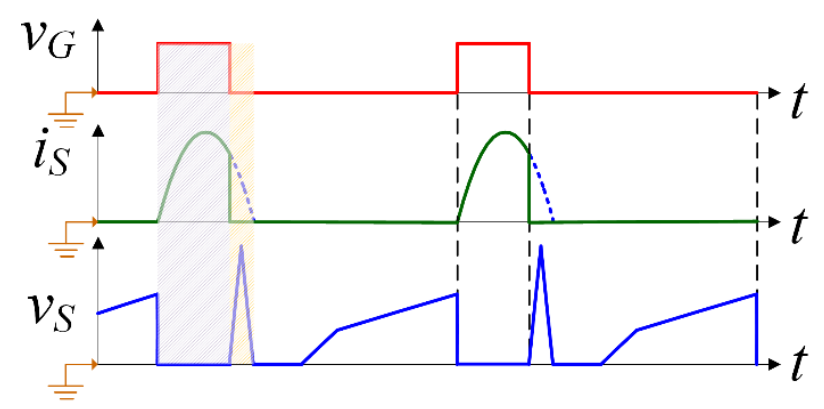

(a)

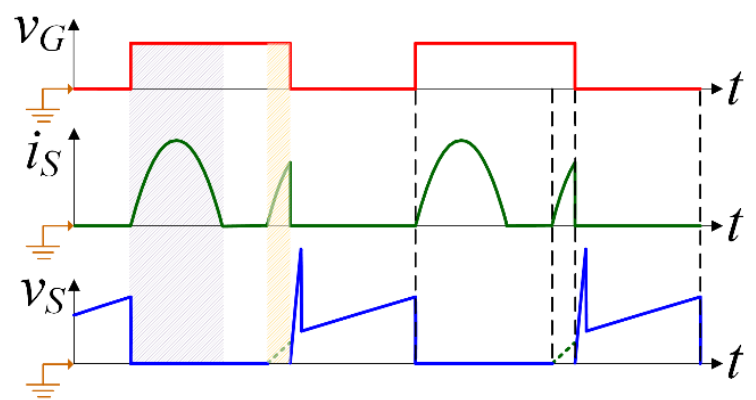

(b)

Figure 9. Theoretical waveforms with mismatch driving signal. (a) $T_{o n}$ is too short and (b) $T_{\text {on }}$ is too long

Regarding the ideal waveforms of the proposed converter, which are shown in Figure 6, ZCS can only be realized during a specified period. Additionally, if the drive signal turns to zero before $i_{S 1}$ decreases to zero, ZCS will not be realized obviously, and this constraint is expressed as Equation (39). 
Besides, if the drive signal remains on after the voltage $v_{S 1}$ increases to zero, $S_{1}$ will be turned on again, and ZCS will not be realized either; the constraint expression is shown in Equation (40).

$$
\begin{gathered}
T_{\text {on }} \geq T_{6} \\
\left\{\begin{array}{c}
T_{\text {on }} \leq T_{6}+T_{\delta} \\
\frac{3 I_{g}}{2 C_{r}} T_{\delta}-\left(V_{\text {out }}-\frac{I_{\text {out }}}{C_{d}} T_{\delta}\right)=0
\end{array}\right.
\end{gathered}
$$

\subsubsection{ZCS Boundary}

Based on the above analysis and the constraints shown in Equations (35)-(40), the $T_{\text {on }}$ range and ZCS boundary can be obtained, when the parameters of the resonant devices vary under the maximum power output condition (380-V input line voltage, 400-V output voltage, 8-Ohm load resistance). Figure 10a,b illustrates the minimum and maximum $T_{\text {on }}$ value to realize ZCS, respectively. The driving frequency to satisfy the maximum output power with resonant device parameters changing is shown in Figure 11.

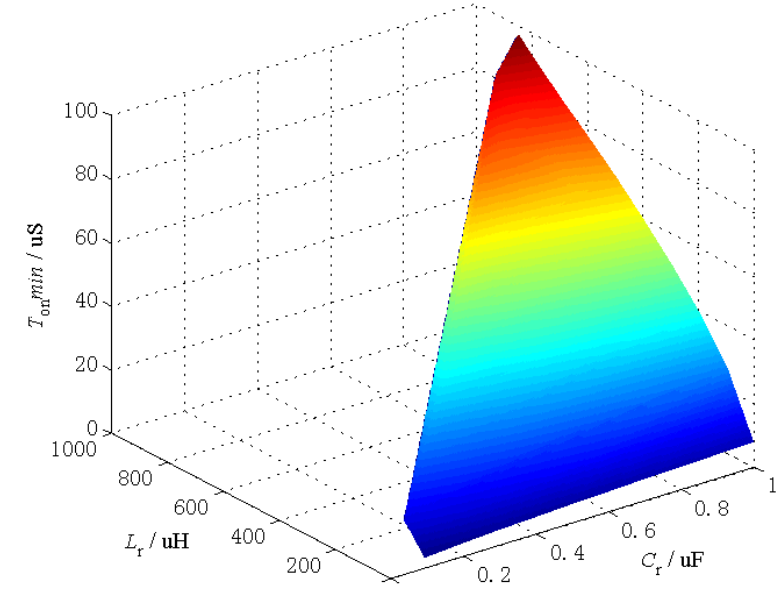

(a)

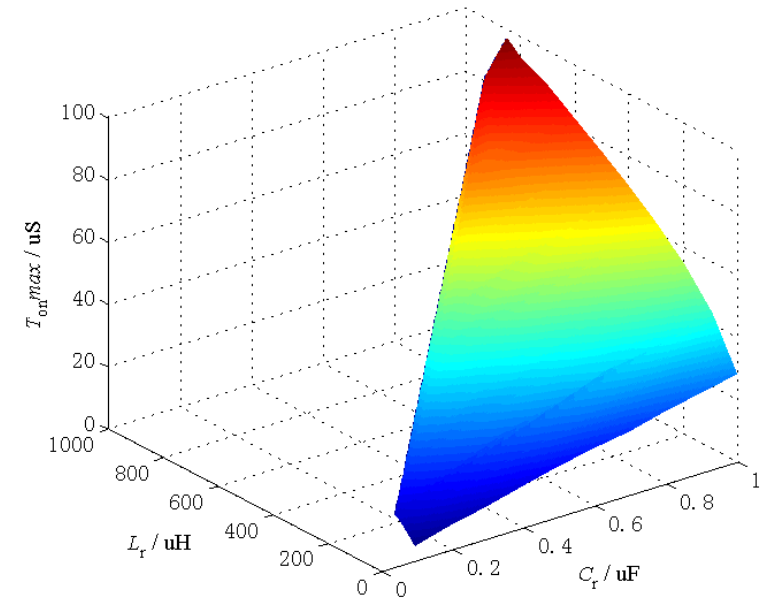

(b)

Figure 10. Minimum and maximum $T_{\text {on }}$ value to realize zero-current-switching (ZCS). (a) minimum $T_{\text {on }}$ and (b) maximum $T_{\text {on }}$.

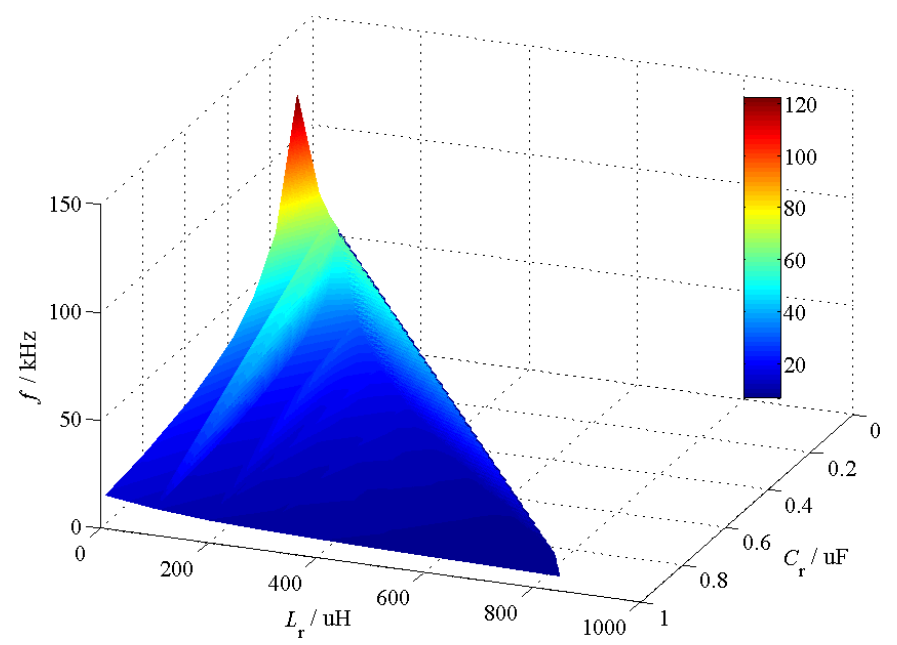

Figure 11. Driving frequency $f$ to realize maximum output power. 


\subsection{ZCS and Battery}

In this section, the cooperative control between ZCS realization and the three-stage battery charging method is studied, and the negative influence of battery charging status on ZCS realization is analyzed. Furthermore, a new method is presented to limit the minimum driving frequency when the battery is in a different status of charging.

In order to optimize the charge cycles and lifetime of EV batteries, we adopt the three-stage charging method. The three stages are: constant current stage, constant voltage stage and floating voltage stage. During the constant current stage, the open-circuit voltage of the battery is about $300 \mathrm{~V}$, and it is charged by a constant current of $50 \mathrm{~A}$. The battery voltage increases with the charging process. When the voltage increases to $400 \mathrm{~V}$, this stage ends, and the constant voltage stage begins. In the constant voltage stage, the charging voltage is $400 \mathrm{~V}$, and the charging current will decrease; this stage ends when the current is below $5 \mathrm{~A}$. The floating voltage stage is actually a low constant voltage stage to ensure a small charging current, to make sure that the battery is truly saturated to extend the service time. During this stage, the charging voltage is $350 \mathrm{~V}$. The charging process and parameter settings are shown in Figure 12 and Table 1. Restricted by the experimental conditions, we use resistor load to simulate the batteries, and the equivalent resistor value is also shown in Figure 12 and Table 1.

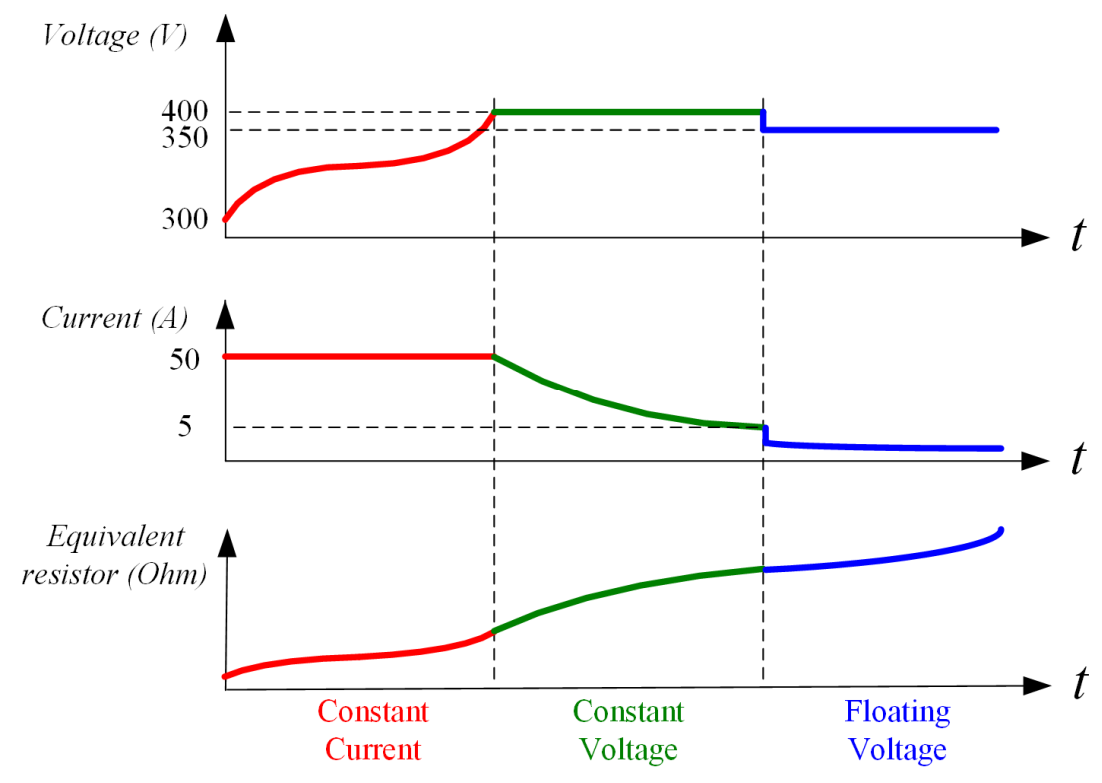

Figure 12. Three-stage charging process.

Table 1. Three-stage charging parameters.

\begin{tabular}{cccc}
\hline Stage & $\mathbf{I}_{\text {out }}(\mathbf{A})$ & $\mathbf{V}_{\text {out }}(\mathbf{V})$ & $\mathbf{R}_{\text {load }}(\mathbf{O h m})$ \\
\hline Constant current & 50 & $300-400$ & $6-8$ \\
Constant voltage & $50-5$ & 400 & $8-80$ \\
Floating voltage & $4.4-2$ & 350 & $80-175$ \\
\hline
\end{tabular}

During the whole process of charging, the fluctuation range of the load equivalent resistance is very large. Just as the parameters shown in Table 1, at the end of the constant current stage, the charging power is the greatest at $20 \mathrm{~kW}$. At the end of the floating voltage process, the minimum charging power 
is $0.7 \mathrm{~kW}$. If we use the PFM control strategy during the whole process, the driving frequency variation range is very large. We select a point of the floating voltage stage as an example. If the equivalent resistor is $100 \mathrm{Ohm}$, the driving frequency should be $5.5 \mathrm{kHz}$ to get a voltage output of $350 \mathrm{~V}$. The simulation waveforms are shown in Figure 13. From Figure 13c, it can be seen that at this working point, the power switch $S$ works under the ZCS condition, while, the driving frequency is very low, so the turn off time is much longer than the resonant period of the resonant tank: $L_{r}, C_{r}$ and $C_{d}$. Therefore, before $S_{1}$ turns on, the resonant components will begin the next resonant cycle. Reactive power will be circulating in the tank, which will reduce the system efficiency and increase the THD of the input current.

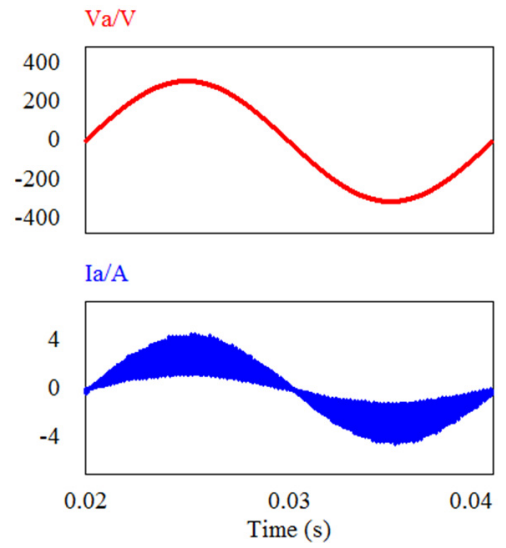

(a)

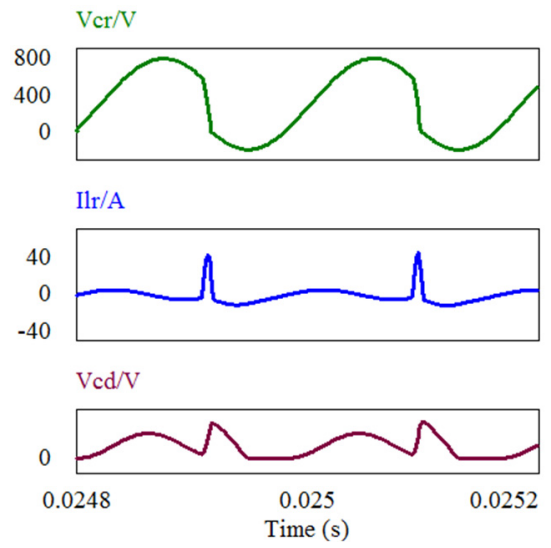

(b)

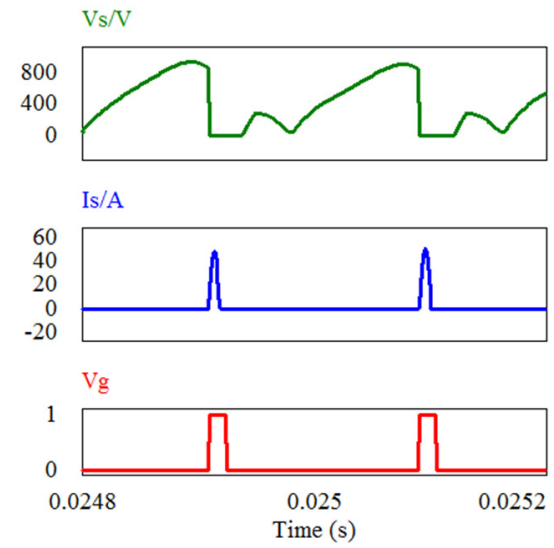

(c)

Figure 13. Simulation waveforms of the floating voltage charging stage. (a) input phase voltage and input phase current; (b) resonant capacitors voltage and resonant inductor current and (c) voltage and current of IGBT and gate signal.

To solve the mentioned problem, we proposed a new control strategy. The complete control method of the system should be as follows: take the PFM control strategy at the beginning of the charging process (the conduction time is constant), and satisfy the output requirements by adjusting the frequency. If the PFM frequency is lower than $10 \mathrm{kHz}$, convert it to the PWM control strategy, keep the fixed driving frequency at $10 \mathrm{kHz}$ and satisfy the output requirements by adjusting the conduction time $T_{\text {on. }}$ The charging process control flow chart is shown in Figure 14.

By using the proposed control strategy, the minimum frequency is set at $10 \mathrm{kHz}$, and the frequency fluctuation will be reduced. Although the PWM strategy cannot guarantee ZCS realization, under the condition of a light load, the conduction losses increase greatly, are greater than the switching losses and seriously affect the system efficiency. Thus, using the PWM control strategy can contribute to the improvement of the system's efficiency. What is more, this strategy can reduce the unexpected resonance on the resonant devices and power switches caused by a sharp drop of the driving frequency under a light load, which will lead to the increase of the input current THD. 


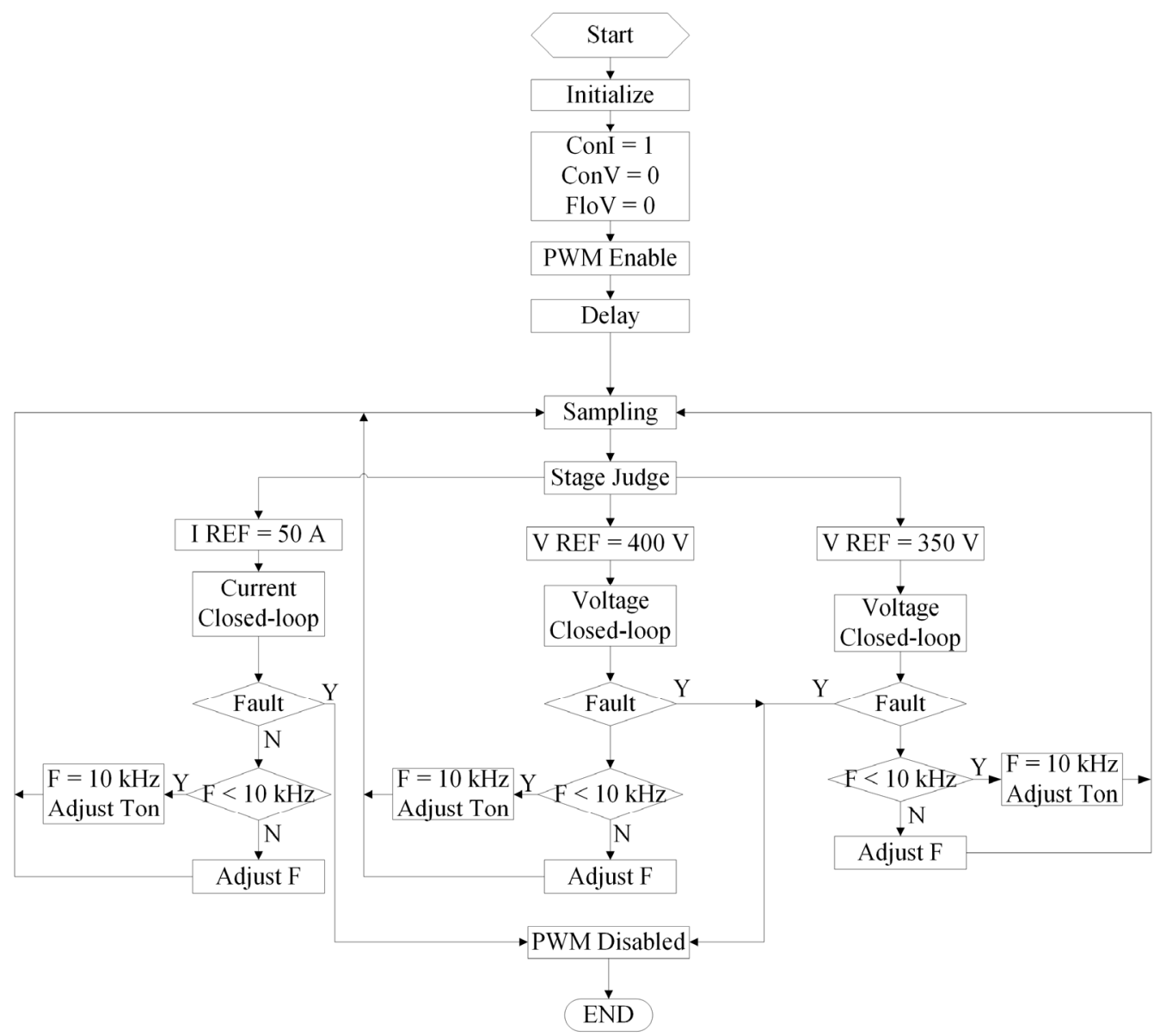

Figure 14. Charging process control flow chart.

\subsection{Optimized Parameters}

Considering the fact that the output voltage and current are changing during the whole charging process, we chose a set of circuit parameters that can ensure ZCS in the whole load range, as shown in Table 2.

Table 2. Main components of the prototype.

\begin{tabular}{cc}
\hline Component & Value \\
\hline Input filter inductors $L_{a}-L_{c}$ & $2 \mathrm{mH}$ \\
Resonant inductor $L_{r}$ & $50 \mu \mathrm{H}$ \\
Output filter inductor $L_{f}$ & $800 \mu \mathrm{H}$ \\
Input side resonant capacitors $C_{r 1}-C_{r 3}$ & $0.65 \mu \mathrm{F}$ \\
Output side resonant capacitor $C_{d}$ & $0.44 \mu \mathrm{F}$ \\
Output filter capacitor $C_{f}$ & $860 \mu \mathrm{F}$ \\
Uncontrolled rectifier diodes $D_{1}-D_{6}$ & C3D25170H \\
Fly-wheel diode $D_{d}$ & C3D25170H \\
Power switch $S_{1}$ & IGW25T1203 in parallel \\
\hline
\end{tabular}

As shown in Table 3, the power devices are selected at the maximum output current and voltage, which are $50 \mathrm{~A}$ and $400 \mathrm{~V}$, respectively. From the interval analysis and Equations (7)-(34), we can 
calculate the voltage and current stresses of the main power devices in the circuit and finally determine the device type as follows.

Table 3. Voltage and current stress of the main power devices.

\begin{tabular}{cccccc}
\hline \multirow{2}{*}{ Component } & $\begin{array}{c}\text { Peak } \\
\text { Voltage (V) }\end{array}$ & $\begin{array}{c}\text { Voltage } \\
\text { RMS (V) }\end{array}$ & $\begin{array}{c}\text { Peak } \\
\text { Current (A) }\end{array}$ & $\begin{array}{c}\text { Current } \\
\text { RMS (A) }\end{array}$ & Value \\
\hline$D_{1}-D_{6}$ & 1170 & 440 & 95 & 20 & C3D25170H \\
$D_{d}$ & 900 & 500 & 25 & 7 & C3D25170H \\
$S_{1}$ & 1100 & 470 & 30 & 12 & IXBH42N170A 3 in parallel \\
$L_{a}-L_{c}$ & - & - & 23 & 16 & - \\
$L_{r}$ & - & - & 65 & 32 & - \\
$L_{f}$ & - & - & 27 & 25 & - \\
$C_{d}$ & 900 & 500 & 65 & 31 & - \\
$C_{r 1}-C_{r 3}$ & 650 & 270 & 75 & 25 & - \\
\hline
\end{tabular}

\subsection{Design of the Inductors}

Besides the power switches and diodes selected above, the design of the inductors is very critical for the system design.

Through the theoretical analysis above, the currents of input filter inductors $L_{a}-L_{c}$ and the output filter inductor $L_{f}$ are sine wave shaped input current and non-oscillatory DC output current, respectively. Thus, the FeSi circular magnetic rings (PPF306060) are chosen to be the magnetic cores of the input and output filter inductors. Since the currents of the resonant inductors are a high-frequency resonant current with an extremely high peak value, a specially designed air gap is needed for the high frequency peak energy storage, and E-shaped magnetic cores (EE110) are selected for the resonant inductors.

\subsubsection{Input Filter Inductor}

According to the theoretical analysis and simulation results, the input filter inductance is $2 \mathrm{mH}$; the peak inductor current is $23 \mathrm{~A}$; and the RMS current is $16 \mathrm{~A}$. We choose the magnetic core PPF306060 and use three cores in parallel. The inductance can be determined by the relative permeability and the effective core parameters as:

$$
L=\frac{4 \pi \mu N^{2} A}{e}
$$

In Equation (41), $\mu$ represents relative permeability; $N$ represents the number of turns; $A$ represents the effective cross-section area; $e$ represents the mean magnetic path length. From the parameters shown in the datasheet of PPF306060, it can be computed that $N=84$.

\subsubsection{Resonant Inductor}

According to the theoretical analysis and simulation results, the resonant inductance is $50 \mu \mathrm{H}$, and the peak inductor current and RMS current are $65 \mathrm{~A}$ and $32 \mathrm{~A}$, respectively. The inductor core is selected as EE110, and the material is PC-40 (MnZn power ferrite material). The turns of this inductor can be calculated as: 


$$
N=\frac{L I_{p}}{A_{e} B_{\max }}
$$

From the datasheet, $A_{e}=1296 \mathrm{~mm}^{2}$ and $B_{\max }=0.39 \mathrm{~T}$. Thus, the turns can be deduced: $N=7$.

\subsubsection{Output Filter Inductor}

According to the simulation results, the output filter inductance is $800 \mu \mathrm{H}$; the peak inductor current is $27 \mathrm{~A}$; and the RMS current is $25 \mathrm{~A}$. We also choose the magnetic core PPF306060 and use three cores in parallel. The number of turns can be calculated in the same way as Equation (41), and the parameters of this core are exactly the same as those of the input filters; finally, $N=54$.

\subsection{Loss Distribution}

In this section, the power losses of the power switches, power diodes, inductors and capacitors at $50 \mathrm{~A}$ and $400 \mathrm{~V}$ output are estimated.

\subsubsection{Power Switches}

When calculating the power switch losses in the maximum power output condition, in view of the ZCS status of the power switches, we ignore the switching losses and only consider the conduction losses. The losses can be calculated by the following expression.

$$
P_{\text {cond }}=D \times V_{C E S A T} \times I_{C}
$$

In Equation (43), $D$ represents the duty ratio, $V_{C E S A T}$ represents the drop voltage of the switch and $I_{C}$ represents the average current flow through the switch.

In the maximum power output condition, the driving frequency is about $35 \mathrm{kHz}$, so $D$ is about 0.53 . The current of each switch can be approximated to a sine wave, shown in Equation (44), from zero to $\pi$. According to the datasheet of the switch, $V_{C E S A T}$ at this point is $2.1 \mathrm{~V}$.

$$
I_{C}=\frac{\left(0.5 I_{\text {out }}+C_{41}\right)}{3} \sin \frac{t}{2 \pi \sqrt{L_{r} C_{d}}}
$$

From Equations (43) and (44), the power loss of each power switch is:

$$
P_{\text {cond }}=0.525 \times 2.1 \times \int_{0}^{15} I_{C} d t=60 \mathrm{~W}
$$

Thus, the total power loss of the 6 IGBTs is: $P_{\mathrm{S}}=6 \times P_{\text {cond }}=360 \mathrm{~W}$.

\subsubsection{Uncontrolled Rectifier Bridge Diodes}

Just like the IGBTs, only conduction losses of the uncontrolled rectifier bridge diodes are considered:

$$
\begin{gathered}
P_{f}=D \times V_{f} \times I_{f} \\
\left\{\begin{array}{l}
V_{f}=V_{T}+I_{f} \times R_{T} \\
R_{T}=0.03+\left(T \times 0.5 \times 10^{-3}\right) \\
V_{T}=0.99-\left(T \times 1.5 \times 10^{-3}\right)
\end{array}\right.
\end{gathered}
$$


According to the parameters shown in the datasheet and the operating point of the diodes, we can get that the power loss of each diode in the uncontrolled rectifier is $25 \mathrm{~W}$.

Therefore, the total power losses of 12 uncontrolled rectifier diodes in the maximum power output condition can be shown as: $P_{\mathrm{DBir}}=12 \times P_{f}=300 \mathrm{~W}$.

\subsubsection{Fly-Wheel Diodes}

The calculating formula of fly-wheel diodes is the same as those of the rectifier diodes shown in Equations (46) and (47). Based on the interval analysis above, the current of the fly-wheel diodes is half of the output current. Thus, we can calculate the power loss for each fly-wheel diode to be about $7 \mathrm{~W}$.

The total power loss of the two fly-wheel diodes in the maximum power output condition is $14 \mathrm{~W}$.

The power dissipation of all the diodes in the OBC is: $P_{\mathrm{D}}=P_{\mathrm{DBir}}+P_{\mathrm{DFly}}=314 \mathrm{~W}$.

\subsubsection{Resonant and Filter Capacitors}

The losses of the capacitors include two parts: dielectric loss and metal loss. The calculating expression is shown in Equations (48) and (49).

$$
\begin{gathered}
P=U I \sin \theta \\
\tan \theta=\tan \theta_{0}+2 \pi f \times C_{n} \times R_{E S R}
\end{gathered}
$$

In Equations (48) and (49), $R_{E S R}$ represents equivalent series resistance, $\tan \theta_{0}$ represents the dielectric dissipation factor and $\tan \theta$ represents the dissipation factor.

For the input side resonant capacitors, the datasheet gives that the $\tan \theta$ is lower than 0.001 , so we select the maximum value 0.001 as the dissipation factor. Considering that the dissipation angle is too small, the sine value can be approximated to the tangent value. Consequently, the power losses of the six input side resonant capacitors can be calculated as: $P_{C r}=6 \times(270 \mathrm{~V} \times 25 \mathrm{~A} \times 0.001)=40.5 \mathrm{~W}$.

The output side resonant capacitors use the same calculation and approximation method as the input side resonant capacitors. We use two $0.22-\mu \mathrm{F}$ capacitors in parallel for each channel. The dissipation factor is lower than 0.006 . Thus, the power losses of the four output side resonant capacitors can be calculated as: $P_{C d}=4 \times(500 \mathrm{~V} \times 5 \mathrm{~A} \times 0.0006)=6 \mathrm{~W}$.

Using the same calculation and approximation method, the power losses of the output filter capacitors can be calculated. We use two $430-\mu \mathrm{F}$ capacitors in parallel for each channel, and the datasheet gives that the dissipation factor is lower than 0.002 at the operating point. Therefore, the power loss of the output filter capacitors is: $P_{\mathrm{Cf}}=2 \times(400 \mathrm{~V} \times 10 \mathrm{~A} \times 0.002)=16 \mathrm{~W}$.

Therefore, the total power losses of the capacitors in the $\mathrm{OBC}$ can be calculated as: $P_{\mathrm{C}}=P_{C d}+P_{C r}+P_{C f}=62.5 \mathrm{~W}$.

\subsubsection{Resonant and Filter Inductors}

The power losses of the inductor can be divided into two parts: core loss and winding loss.

For the magnetic core PPF306060, the core loss can be decided by the flux density and working frequency. The flux density can be calculated by the following expression. 


$$
\begin{gathered}
B=\frac{0.4 \pi \mu N I}{l} \\
P_{\text {core }}=0.42 B^{2.2} f^{1.87} \times V
\end{gathered}
$$

where $B$ represents flux density $(\mathrm{kG}) ; \mu$ represents relative permeability; $N$ represents the number of turns; $l$ means magnetic path length $(\mathrm{cm})$; $I$ represents peak magnetic current $(\mathrm{A}) ; f$ represents the working frequency $(\mathrm{kHz})$ and $V$ represents the volume of the magnetic core $\left(\mathrm{cm}^{3}\right)$.

The winding loss is the heat loss caused by the coil resistance, and it can be calculated by Ohm's law, shown in following expression.

$$
P_{\text {wind }}=I^{2} R
$$

From Equations (50)-(52), we can get the power losses of the six input filter inductors and the two output filter inductors, respectively, as: $P_{\text {Lin }}=6 \times\left(P_{\text {core }}+P_{\text {wire }}\right)=72 \mathrm{~W} ; P_{\mathrm{Lf}}=2 \times\left(P_{\text {core }}+P_{\text {wire }}\right)=24 \mathrm{~W}$.

For the resonant inductor, the winding loss is very small compared to the core loss. The core is designed as PC-40 EE110, where $V_{e}=336,420 \mathrm{~mm}^{3}$. According to the datasheet, the core loss per volume is obtained as: $P_{c v}=0.0004 \mathrm{~W} / \mathrm{mm}^{3}$ at $60^{\circ} \mathrm{C}$. As a result, the core losses of two resonant inductors are:

$$
P_{L r}=2 \times\left(V_{\mathrm{e}} \cdot P_{\mathrm{cv}}\right)=269 \mathrm{~W}
$$

Thus, the total power losses of the inductors in the system can be shown as: $P_{L}=P_{L r}+P_{L i n}+P_{L f}=365 \mathrm{~W}$.

Finally, based on the calculation results shown in Equations (43)-(53), the conversion efficiency at the $20-\mathrm{kW}$ output condition can be deduced as:

$$
\eta_{\%}=\frac{P_{\text {out }}}{P_{\text {out }}+P_{S}+P_{D}+P_{C}+P_{L}} \times 100 \%=94.8 \%
$$

A power loss distribution under a $20-\mathrm{kW}$ load is shown in Figure 15 . It can be concluded that the dissipation of this OBC mainly centralizes at the IGBTs, resonant inductors and bridge diodes. Additionally, this will be verified in the experiment section.

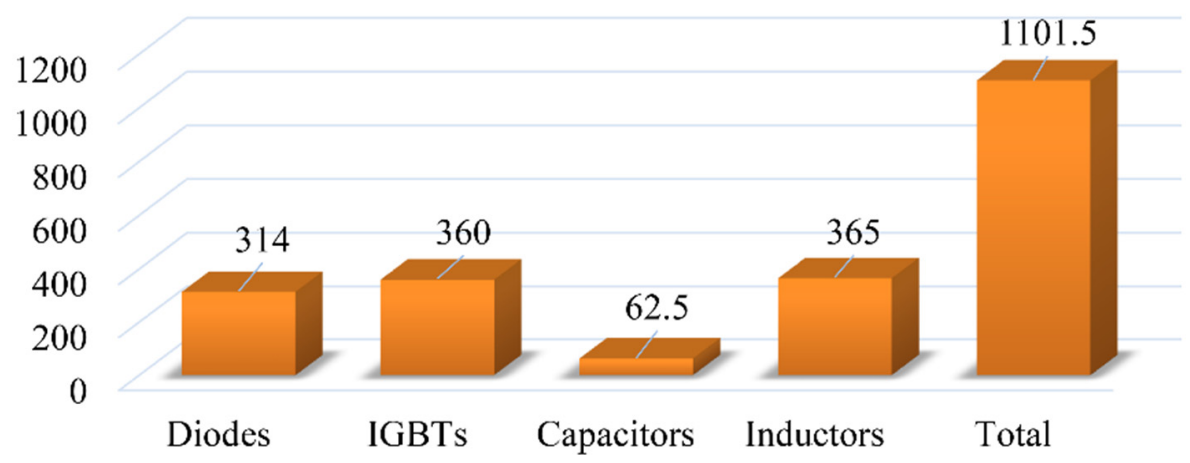

Figure 15. Power loss distribution.

\section{Simulation and Experiment}

In order to verify the efficiency, PFC and THD of the proposed topology and the accuracy of the theoretical analysis above, we established a simulation model. Furthermore, a hardware platform was built for the experimental research. 


\subsection{Simulation Result}

\subsubsection{Simulation at Maximum Output Power}

Figure 16 illustrates the simulation waveforms of the proposed topology at the maximum output power (50-A current and 400-V voltage). There are two parallel interleaved channels in the circuit, and the driving signals have a 180-degree phase shift from each other. Figure 16a shows the waveforms of the input line current with its AC phase voltage and output voltage. Figure 16b shows the details of the IGBT voltage and current. Figure 16c shows the voltage waveforms of the resonant capacitors $C_{r}$ and $C_{d}$ and the current of the resonant inductor $L_{r}$.

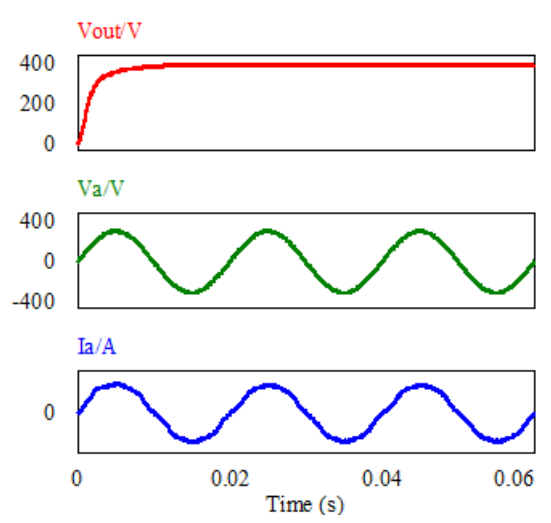

(a)

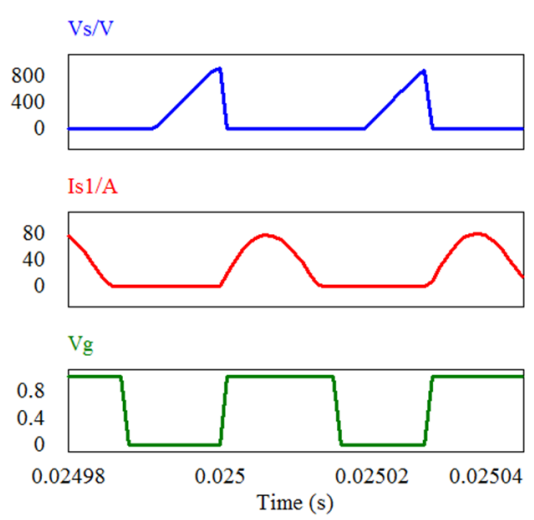

(b)

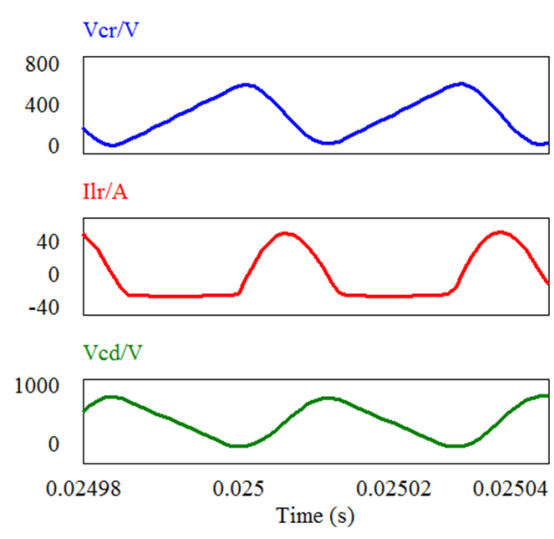

(c)

Figure 16. Simulated waveforms under 20-kW maximum output power: (a) input current, input and output voltage; (b) voltage and current of IGBT; (c) voltage of resonant devices.

The simulation results indicate that the proposed topology can realize the maximum output power at $34.5 \mathrm{kHz}$; the measured THD of the input current is $3.5 \%$, and PF is 0.998 . Besides, the detailed waveforms of the resonant components are consistent with the theoretical analysis results. The voltage and current waveforms of the IGBT show that the buck switches can realize ZCS at the maximum output power.

\subsubsection{Simulation of the Proposed Control Strategy}

In order to verify the effectiveness of the proposed control strategy, two groups of simulations under a low-power condition with traditional PFM control and the proposed hybrid PFM control method are compared in Figure 18. Take the charging process ending point for example, for which the output voltage and current are $350 \mathrm{~V}$ and $2 \mathrm{~A}$, respectively. For these two groups of simulations, the input and output conditions are the same: $380-\mathrm{V}$ input line voltage, $350-\mathrm{V}$ output voltage and 2-A output current.

Figure $17 \mathrm{a}$ shows the input voltage and current of phase $a$ under a $5-\mathrm{kHz}$ driving frequency and a 15 - $\mu$ s turn on time. $I_{a 1}$ is the input current of a single channel, and $I_{a}$ is the input current of phase $a$. The results indicate that the interleaved structure will reduce the input current ripple obviously. However, $I_{a}$ under the PFM control strategy has a great fluctuation, and the THD is about $41.2 \%$. Figure $17 \mathrm{~b}$ shows the input voltage and current of phase $a$ under a $10-\mathrm{kHz}$ driving frequency and a 5.8 - $\mu$ s turn on time. It can be seen that the proposed control strategy eliminates the phase shift between $V_{a}$ and $I_{a}$, and the THD of 
$I_{a}$ decreases to $25.1 \%$. Therefore, by adopting the new proposed hybrid PFM control method, the quality of the input current waveform can be improved obviously.

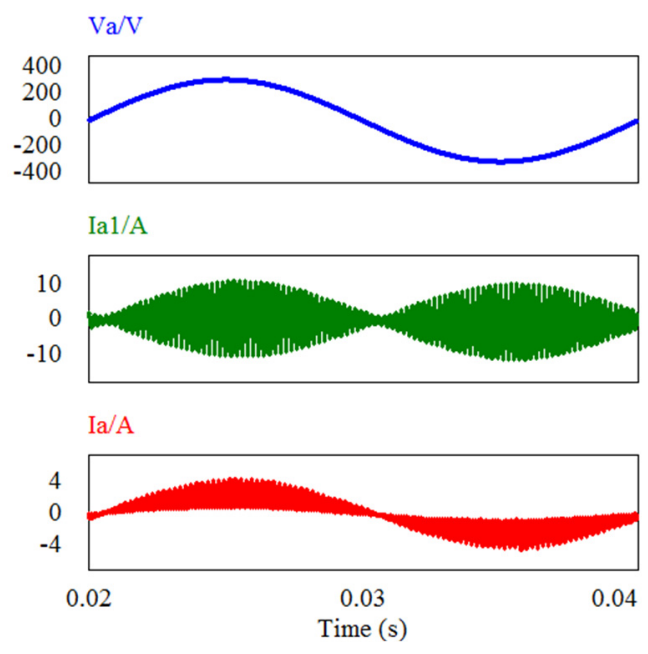

(a)

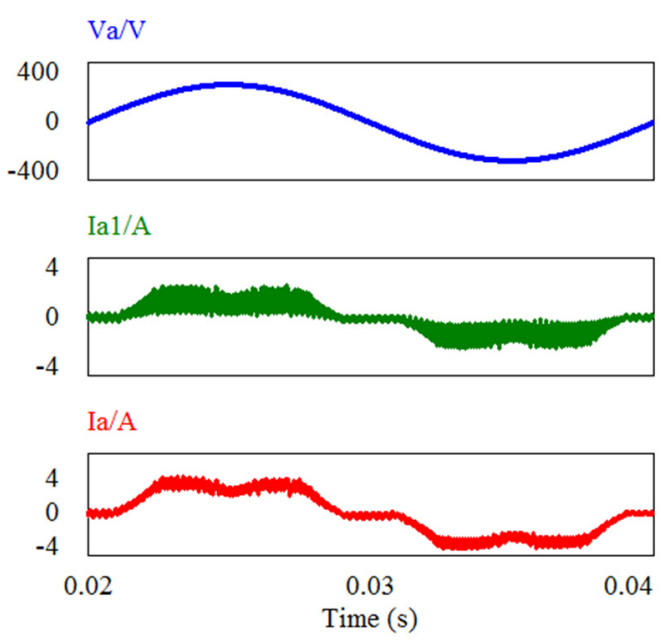

(b)

Figure 17. Simulated waveforms: (a) PFM; (b) the proposed hybrid PFM control strategy.

\subsubsection{Simulation under Imbalanced Current Condition}

Besides the simulations based on equally-shared input currents for the two parallel circuits above, the condition under an imbalanced current is also simulated. In this situation, the resonant inductors $L_{r}$ and $L_{r s}$ are set to be $50 \mu \mathrm{H}$ and $20 \mu \mathrm{H}$ separately, and the output is $20 \mathrm{~kW}$.

The simulation waveforms of the two paralleled channels use the same driving signals with a 180-degree phase shift from each other and are shown in Figure 18a. At this time, the driving frequency of both channels is $35 \mathrm{kHz}$. In Figure 18a, $0.2 V_{a}$ and input current $I_{a}$ are compared to illustrate PF of the system, $V_{o u t}$, and the contrast between $I_{a 1}$ and $I_{a 2}$ is also shown in Figure 18a. By calculation, we can get the RMS value, THD and PF of $I_{a 1}, I_{a 2}$ and $I_{a}$, as shown in Table 4.

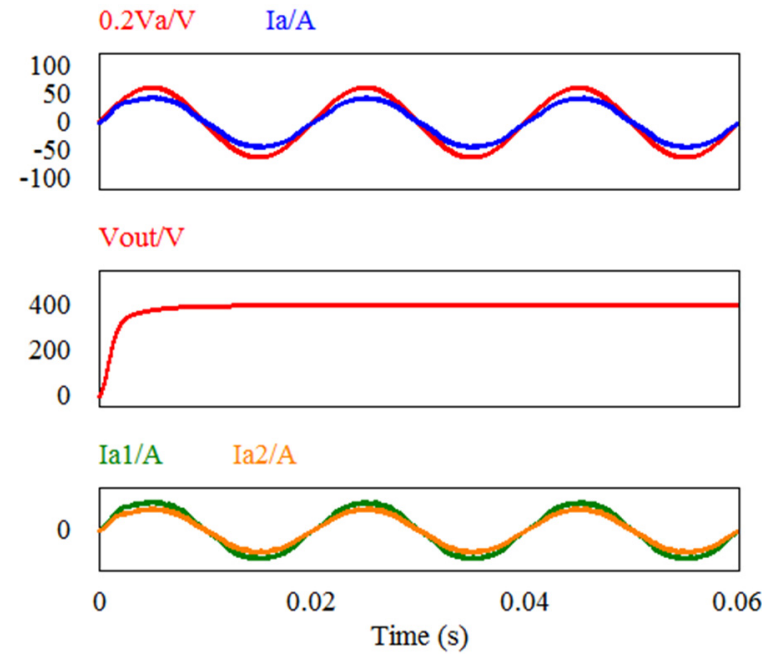

(a)

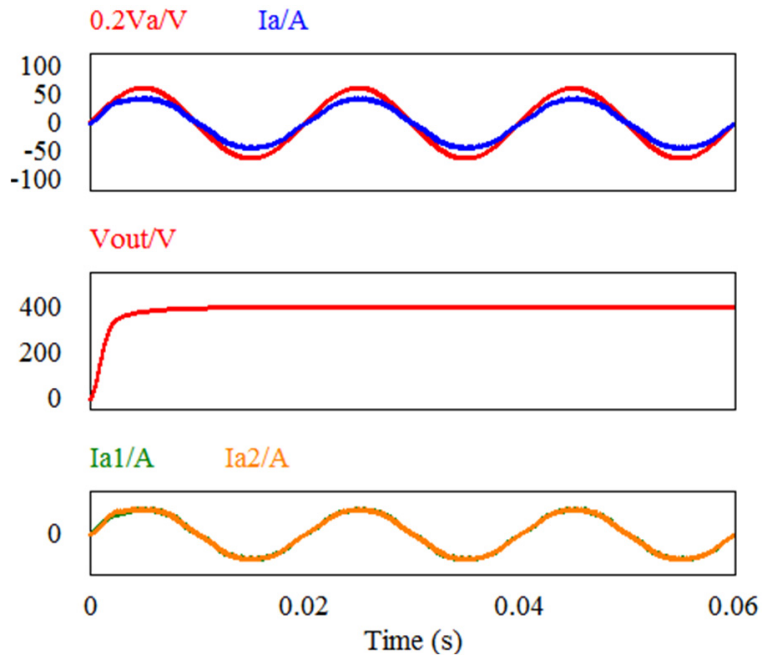

(b)

Figure 18. Simulated waveforms under the imbalanced current condition: (a) two channels with a synchronous drive; (b) the current sharing control strategy. 
Although the current imbalance has no effect on the PF and THD of the circuit, it will cause the uneven distribution of heat, which will limit the increase of the system power. Therefore, a current sharing control strategy can be used: the current of two paralleled circuits can be equally shared by adjusting the driving frequency of the two paralleled circuits respectively when the circuit parameters are not exactly the same. The simulation results using the current sharing control strategy are shown in Figure 18b. Additionally, the statistic parameters are also shown in Table 4.

Table 4. Simulation results' contrast under balanced and imbalanced current.

\begin{tabular}{cccccccccccccc}
\hline \multicolumn{2}{c}{$\begin{array}{c}\text { Resonant } \\
\text { Inductor }(\boldsymbol{\mu H})\end{array}$} & \multicolumn{2}{c}{$\begin{array}{c}\text { Driving } \\
\text { Frequency (kHz) }\end{array}$} & \multicolumn{2}{c}{$\begin{array}{c}\text { Input Current } \\
\text { RMS (A) }\end{array}$} & \multicolumn{3}{c}{ THD (\%) } & \multicolumn{4}{c}{ PF } \\
\hline $\boldsymbol{L}_{\boldsymbol{r}}$ & $\boldsymbol{L}_{\boldsymbol{r} \boldsymbol{s}}$ & $\boldsymbol{f}_{\mathbf{1}}$ & $\boldsymbol{f}_{\boldsymbol{2}}$ & $\boldsymbol{I}_{\boldsymbol{a}}$ & $\boldsymbol{I}_{\boldsymbol{a} \mathbf{1}}$ & $\boldsymbol{I}_{\boldsymbol{a} \mathbf{2}}$ & $\boldsymbol{I}_{\boldsymbol{a}}$ & $\boldsymbol{I}_{\boldsymbol{a} \mathbf{1}}$ & $\boldsymbol{I}_{\boldsymbol{a} \mathbf{2}}$ & $\boldsymbol{I}_{\boldsymbol{a}}$ & $\boldsymbol{I}_{\boldsymbol{a} \mathbf{1}}$ & $\boldsymbol{I}_{\boldsymbol{a} \mathbf{2}}$ \\
\hline 50 & 50 & 33.0 & 33.0 & 31.2 & 15.6 & 15.6 & 3.46 & 4.13 & 4.13 & 0.998 & 0.998 & 0.998 \\
50 & 20 & 35.0 & 35.0 & 30.9 & 17.5 & 13.3 & 3.08 & 4.30 & 3.00 & 0.998 & 0.998 & 0.998 \\
50 & 20 & 32.9 & 38.2 & 31.0 & 15.5 & 15.5 & 3.46 & 4.13 & 3.43 & 0.998 & 0.998 & 0.998 \\
\hline
\end{tabular}

\subsection{Experiment Result}

To verify the performance of the proposed topology, a prototype based on the previous study is built. Freescale MCU is used as the monolithic digital controller. Figure 19 is the photo of the prototype.

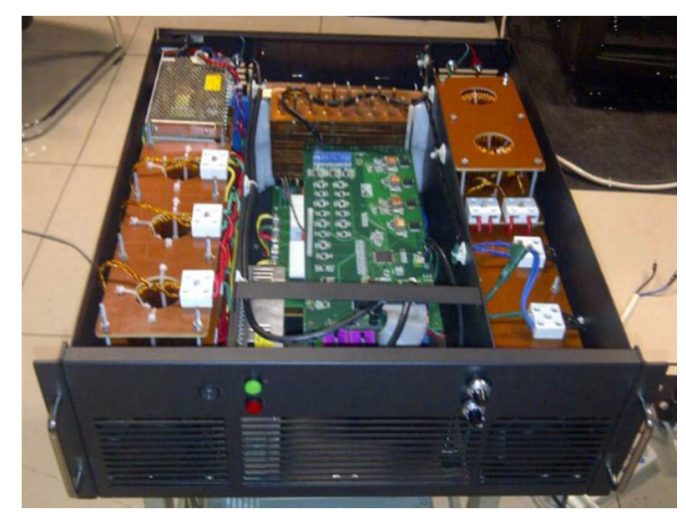

Figure 19. Prototype of the proposed topology.

\subsubsection{Maximum Output Power Experiment}

Restricted by experimental conditions, the maximum output power experiment can only be done at $8.5 \mathrm{~kW}$. The experiment result of a $200-\mathrm{V}$ output at a $6-\mathrm{Ohm}$ load is presented in Figure 20. Figure 20a shows the input line voltage, input phase $a$ current and output current. Figure $20 \mathrm{~b}$ shows the envelope of the IGBT voltage $v_{S}$, IGBT current $i_{S}$, resonant inductor $L_{r}$ current $i_{L r}$ and output current of the single channel $0.5 i_{\text {out }}$. Figure $20 \mathrm{c}$ is the enlarged waveforms of Figure 20b, from which we can see that the IGBT realized ZCS and was completely consistent with the theoretical analysis waveforms shown in Section 3. Figure $20 \mathrm{~d}$ is the thermal image, and the maximum temperature is about 46.8 degrees centigrade in the steady state. The concrete data of this experiment are as follows: input line voltage: $230 \mathrm{~V}$; driving frequency: $30 \mathrm{kHz}$; turn on time $T_{\text {on }}: 15 \mu \mathrm{s}$; output voltage: $200 \mathrm{~V}$; load resistance: 6 Ohm; input current THD: 4.3\%; PF: 0.98 and efficiency: 93.7\%. 


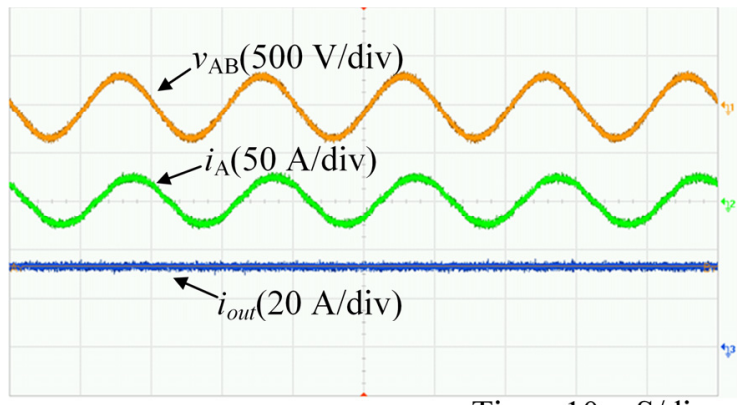

(a)

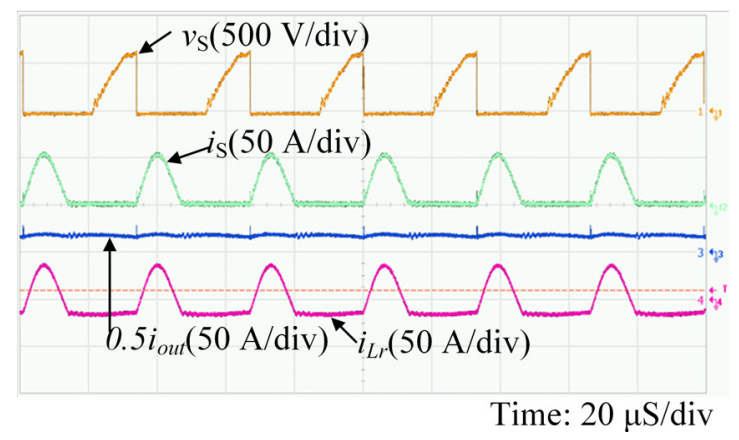

(c)

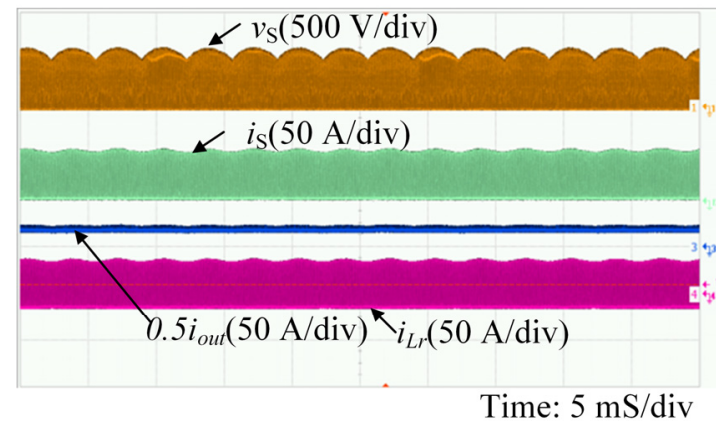

(b)

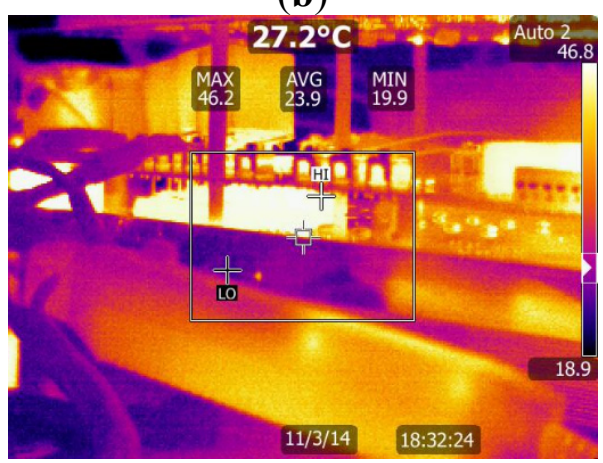

(d)

Figure 20. Experimental results (230-V input line voltage, $200-\mathrm{V}$ output, 6-Ohm load resistance): (a) input voltage, input and output current; (b) envelop of resonant voltage and current; (c) enlarged waveform of resonant voltage and current; (d) thermal image.

\subsubsection{Three-Stage Charging Process Experiment}

The three-stage charging process is implemented by equivalent experiments, in which several variable high-power resistors are used as the load. In order to avoid overheating, the charging process is only fulfilled at the low-power level. The experimental parameters of three-stage charging are shown in Table 5.

Figure 21a shows the collector-emitter (C-E) voltage and current of the IGBT and the output current at a $70-\mathrm{V}$ input line voltage. The driving frequency reached the upper limit of $40 \mathrm{kHz}$, and the output current is $9.2 \mathrm{~A}$. Figure $21 \mathrm{~b}$ shows the same parameters at a $90-\mathrm{V}$ input line voltage; at this time, the driving frequency is $29 \mathrm{kHz}$, and the output current is $10 \mathrm{~A}$. Comparing these experimental results, it can be concluded that the proposed control method can satisfy the requirements of constant current charging by adjusting the driving frequency, and even when the load or frequency changes, this circuit still can realize ZCS.

Table 5. Three-stage charging process parameter setting.

\begin{tabular}{cccc}
\hline Stage & Output Voltage (V) & Output Current (A) & Load Resistance (Ohm) \\
\hline Constant current & - & 10 & 9 \\
Constant voltage & 120 & - & 15 \\
Floating voltage & 100 & - & 40 \\
\hline
\end{tabular}

Note: In this table, “-” means that at that stage, this value is not a parameter that needs to be controlled. 


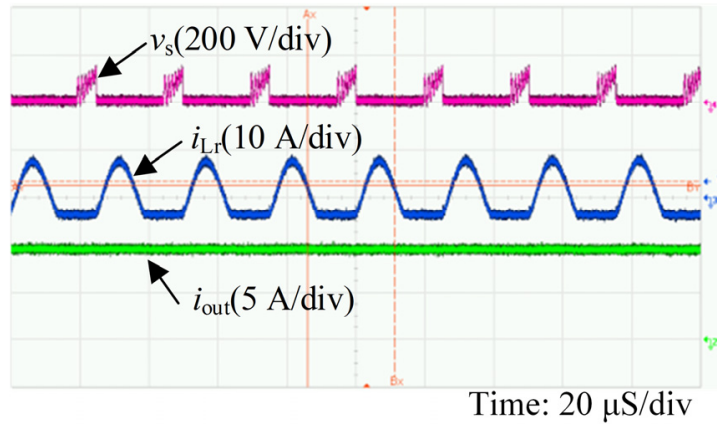

(a)

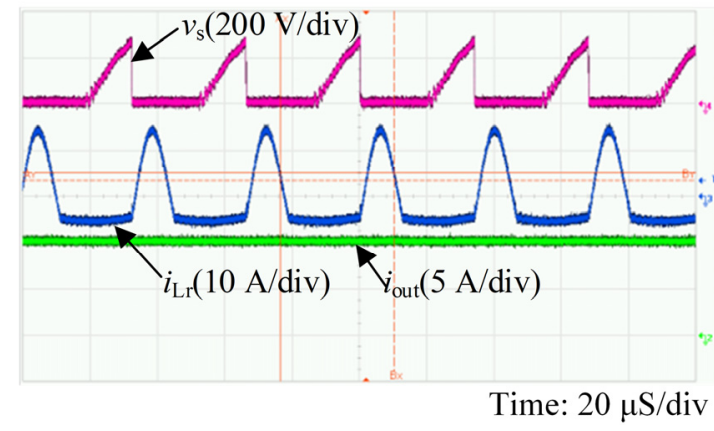

(b)

Figure 21. Experimental results under constant current charging: (a) 70-V line in; (b) 90-V line in.

Two groups of experimental results under the constant voltage stage are also compared in Figure 22. Figure 22a shows the C-E voltage and current of the IGBT and output current at a $90-\mathrm{V}$ input line voltage. The driving frequency reached the upper limit of $40 \mathrm{kHz}$, and the output voltage is $106.8 \mathrm{~V}$. Figure $22 \mathrm{~b}$ shows the same parameters at a $110-\mathrm{V}$ input line voltage. The driving frequency is $25 \mathrm{kHz}$, and the output voltage is $120.1 \mathrm{~V}$. Constant voltage charging and ZCS are realized.

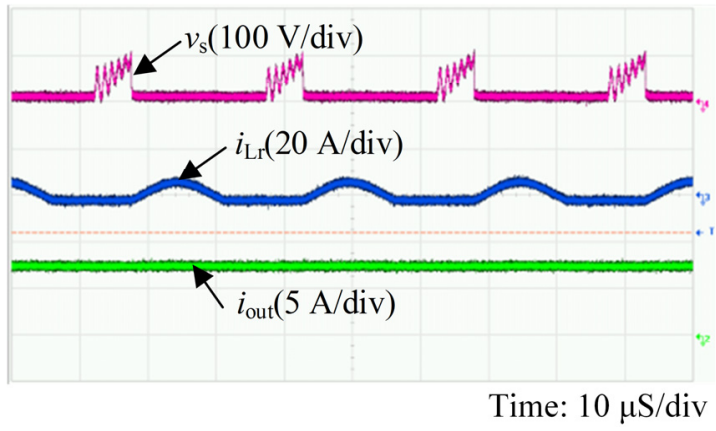

(a)

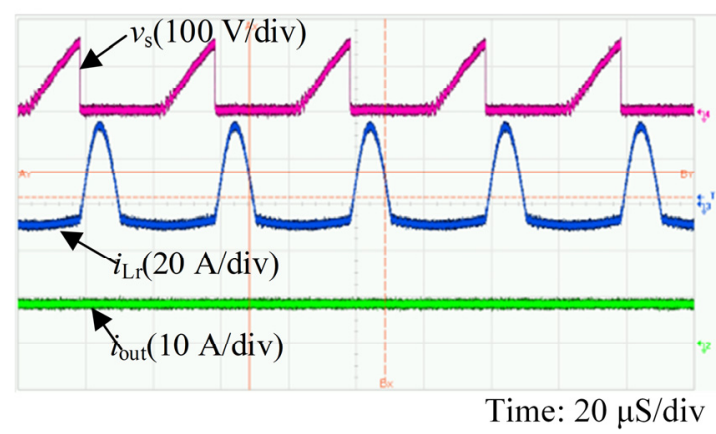

(b)

Figure 22. Experimental results under the constant voltage charging stage (a) $106.8 \mathrm{~V}$ out; (b) $110 \mathrm{~V}$ out.

The experimental results of floating charging stage are shown in Figure 23. Figure 23b is the enlarged waveforms of Figure 23a. It also shows the C-E voltage and current of the IGBT and output current at a $120-\mathrm{V}$ input line voltage; at this condition, the driving frequency is $25 \mathrm{kHz}$ and the output current $2.5 \mathrm{~A}$, and the load resistance is $40 \mathrm{Ohm}$. In this case, ZCS is also realized in the possible load range.

Figure 24 shows the experimental waveforms in the process of charging state switching. Figure 24a shows the waveforms of the transformational transition from the constant current stage to the constant voltage stage. During this interval, the output current $i_{\text {out }}$ turns to $8 \mathrm{~A}$ from $10 \mathrm{~A}$ in $2.5 \mathrm{~ms}$. Figure $24 \mathrm{~b}$ shows the switching point from the constant voltage charging stage to the floating voltage charging stage, where $i_{\text {out }}$ turns from 8 A down to $2.5 \mathrm{~A}$ within $3.2 \mathrm{~ms}$. It can be concluded that the built OBC platform can realize the switching of three charging stages smoothly without obvious overshoot and oscillation. 


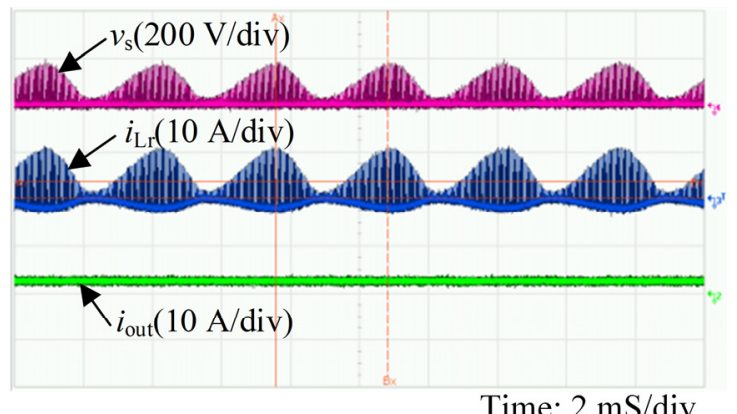

(a)

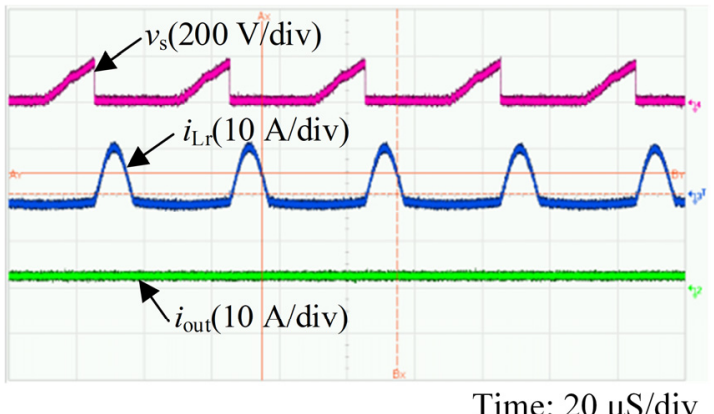

(b)

Figure 23. Experiment results under the floating voltage charging stage.

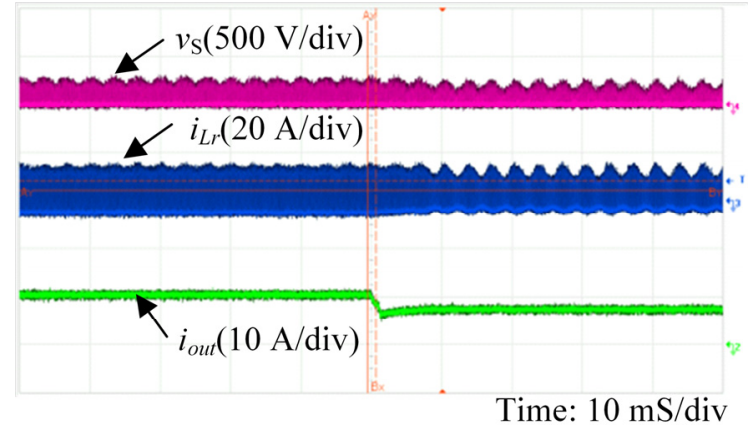

(a)

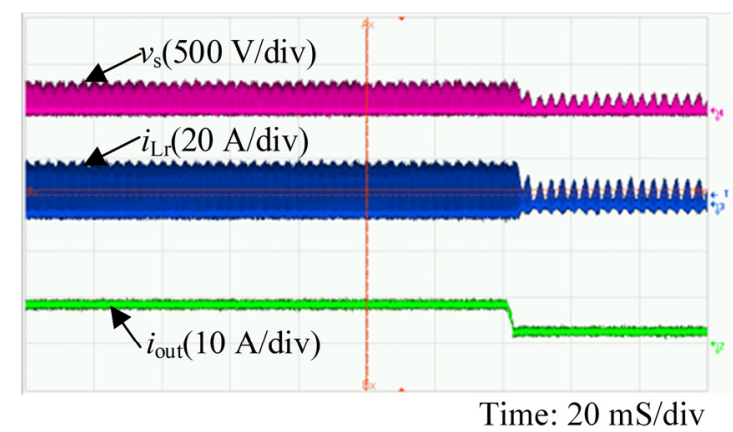

(b)

Figure 24. Experimental results under the mode transition point.

After a series of experiments, the efficiency, THD and PF of this OBC platform under different output powers are obtained and shown in Figure 25. It is shown that, with the power increases, the efficiency stays in a stable range between $93.5 \%$ and $94.0 \%$. At the maximum output condition, the THD is about $4.3 \%$, and PF is about 0.98 .

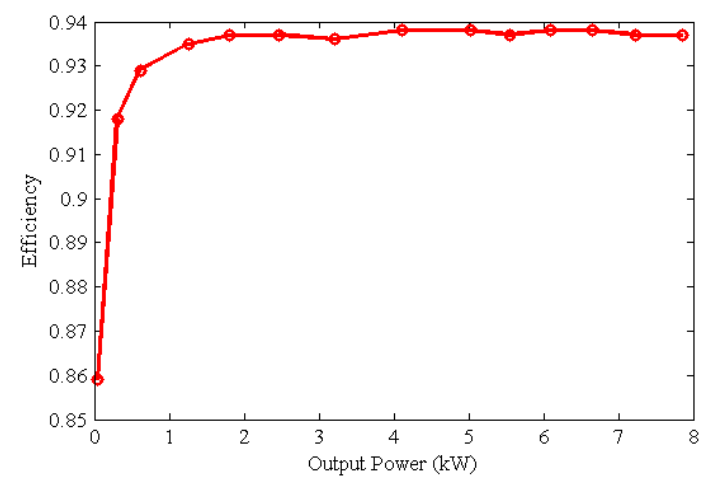

(a)

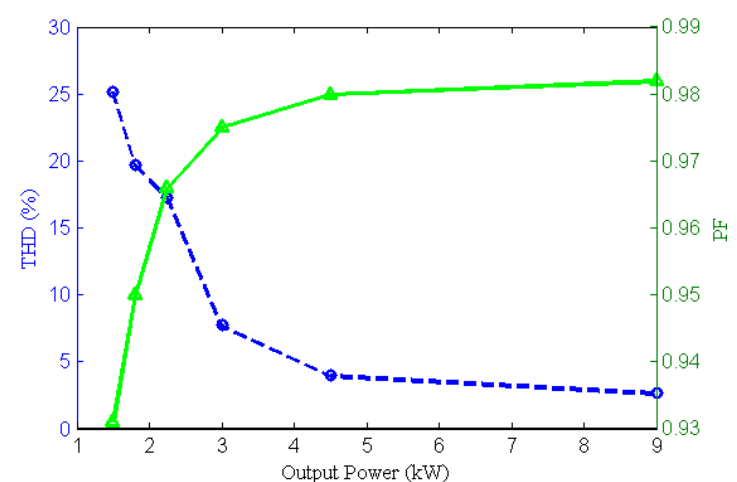

(b)

Figure 25. Measured efficiency, total harmonic distortion (THD) and PF curves: (a) efficiency; (b) THD and PF.

\section{Conclusions}

This paper proposed a three-phase interleaved high-efficiency and high power factor ZCS OBC for EV application. By using the multi-resonant structure, the buck switch can realize ZCS and can achieve 
a high-quality input current waveform with high PF and low THD. The ZCS constraint conditions were deduced under a battery load. A hybrid PFM control method based on the battery load requirements during the three-stage charging process is also proposed. This method combines the PFM and PWM strategy and keeps the driving frequency in a range of $10 \mathrm{kHz}-40 \mathrm{kHz}$, to avoid the power losses caused by the reactive power transmission and resonance at a low frequency.

The performance of the proposed charger has been verified through experimental results based on the built prototype platform. Due to the power upper limit of the AC source, the maximum output power experiment was done at $8.5 \mathrm{~kW}$ only. The efficiency is above $93.5 \%$, and THD and PF remain around $4.3 \%$ and 0.98 , respectively. Moreover, simulations and experimental results were verify the theoretical analysis. It is shown that the proposed interleaved three-phase high-power ZCS buck rectifier is suitable for high-frequency and high-efficiency OBC applications.

\section{Acknowledgments}

This research was supported by the National Natural Science Foundation of China (Grant: 51307117) and supported by Tianjin Municipal Science and Technology Commission (Grant: 14ZCZDGX00035). The authors would also like to thank the anonymous reviewers for their valuable comments and suggestions to improve the quality of the paper.

\section{Author Contributions}

Cheng-Shan Wang, Wei Li and Yi-Feng Wang designed the main parts of the study, including the circuit simulation model, topology innovation and simulation development. Zhun Meng helped in the hardware development and experiment. Jie-Gui Zhou were also responsible for writing the paper.

\section{Conflicts of Interest}

The authors declare no conflict of interest.

\section{References}

1. Yilmaz, M.; Krein, P.T. Review of battery charger topologies, charging power levels, and infrastructure for plug-in electric and hybrid vehicles. IEEE Trans. Power Electron. 2013, 28, 2151-2169.

2. Hawkins, T.R.; Gausen, O.M.; Strømman, A.H. Environmental impacts of hybrid and electric vehicles-A review. Int. J. Life Cycle Assess. 2012, 17, 997-1014.

3. Haghbin, S.; Lundmark, S.; Alaküla, M.; Carlson, O. Grid-connected integrated battery chargers in vehicle applications: Review and new solution. IEEE Trans. Ind. Electron. 2013, 60, 459-473.

4. Chan, C.C.; Chau, K.T. An overview of power electronics in electric vehicle. IEEE Trans. Ind. Electron. 1997, 44, 3-13.

5. Mapelli, F.L.; Tarsitano, D.; Mauri, M. Plug-in hybrid electric vehicle: Modeling, prototype realization, and inverter losses reduction analysis. IEEE Trans. Ind. Electron. 2010, 57, 598-607.

6. Musavi, F.; Edington, M.; Eberle, W.; Dunford, W.G. Evaluation and efficiency comparison of front end AC-DC plug-in hybrid charger topologies. IEEE Trans. Smart Grid 2012, 3, 413-421. 
7. Li, W.; Zong, S.; Liu, F.; Yang, H.; He, X.; Wu, B. Secondary-side phase-shift-controlled ZVS DC/DC converter with wide voltage gain for high input voltage applications. IEEE Trans. Power Electron. 2013, 28, 5128-5139.

8. Kim, Y.-D.; Cho, K.-M.; Kim, D.-Y.; Moon, G.-W. Wide-range ZVS phase-shift full-bridge converter with reduced conduction loss caused by circulating current. IEEE Trans. Power Electron. 2013, 28, 3308-3316.

9. Jang, Y.; Jovanović, M.M.; Chang, Y.-M. A new ZVS-PWM full-bridge converter. IEEE Trans. Power Electron. 2003, 18, 1122-1129.

10. Mishima, T.; Nakaoka, M. Practical evaluations of a ZVS-PWM DC-DC converter with secondary-side phase-shifting active rectifier. IEEE Trans. Power Electron. 2011, 26, 3896-3907.

11. Wang, H.; Dusmez, S.; Khaligh, A. Design and analysis of a full-bridge LLC-based PEV charger optimized for wide battery voltage range. IEEE Trans. Veh. Technol. 2014, 63, 1603-1613.

12. Deng, J.; Li, S.; Hu, S.; Mi, C.C.; Ma, R. Design methodology of LLC resonant converters for electric vehicle battery chargers. IEEE Trans. Veh. Technol. 2014, 63, 1581-1592.

13. Beiranvand, R.; Rashidian, B.; Zolghadri, M.R.; Alavi, S.M.H. Using LLC resonant converter for designing wide-range voltage source. IEEE Trans. Ind. Electron. 2011, 58, 1746-1756.

14. Singh, B.; Singh, B.N.; Chandra, A.; al-Haddad, K.; Pandey, A.; Kothari, D.P. A review of three-phase improved power quality AC-DC converters. IEEE Trans. Ind. Electron. 2004, 51, 641-660.

15. Jang, Y.; Erickson, R.W. New single-switch three-phase high power factor rectifiers using multi-resonant zero current switching. In Proceedings of the IEEE Applied Power Electronics Conference, New York, NY, USA, 13-17 February 1994; pp. 711-717.

16. Lee, J.H.; Jung, D.-Y.; Park, S.-H.; Lee, T.-K.; Kim, Y.-R.; Won, C.-Y. Battery charging system for PHEV and EV using single phase AC/DC PWM buck converter. J. Electr. Eng. Technol. 2012, 7, 736-744.

17. Pouliquen, H.; Buchheit, N.; Lethelliez, J. Control of a single-switch three-phase rectifier operating in continuous conduction mode. In Proceedings of the 5th International Conference on Power Electronics and Variable-Speed Drives, London, UK, 26-28 October 1994; pp. 301-306.

18. Williams, B.W.; Moud, M.M.; Tooth, D.; Finney, S.J. A three phase AC to DC converter with controllable displacement factor. In Proceedings of the PESC'95-Power Electronics Specialist Conference, New York, NY, USA, 18-22 June 1995; pp. 996-1000.

19. Wang, K.; Boroyevich, D.; Lee, F.C. Charge control of three-phase buck PWM rectifiers. In Proceedings of the APEC 2000 - Applied Power Electronics Conference, Piscataway, NJ, USA, 6-10 February 2000; pp. 824-831.

20. Ismail, E.H.; Erickson, R.W. A single transistor three-phase resonant switch for high quality rectification. In Proceedings of the IEEE Power Electronics Specialists Conference, Toledo, Spain, 29 June-3 July 1992; pp. 1341-1351.

21. Jang, Y.; Jovanović, M.M. Design considerations and performance evaluation of 6-kW, single-switch, three-phase, high-power-factor, multi-resonant, zero-current-switching buck rectifier. In Proceedings of the Telecommunications Energy Conference, New York, NY, USA, 19-23 October 1997; pp. 715-722. 
22. Chiu, H.-J.; Lo, Y.-K.; Tseng, P.-J.; Liu, Y.-C.; Chang, Y.-C.; Liao, Y.-M.; Jen, K.-K.; Fu, K.-S.; Chung, C.-H.; Chen, K.-F. Design and implementation of high-efficiency $\mathrm{LiFePO}_{4}$ battery charger for electric vehicle applications. Int. J. Circ. Theor. Appl. 2014, 42, 759-768.

23. Pai, K.-J.; Chien, M.-D.; Hsieh, C.-C.; Cheng, M.-Y.; Liang, C.-K.; Lo, Y.-K.; Liu, Y.-C.; Tseng, P.-J. Implementation and design of high-power fast charger for lithium-ion battery pack. Int. J. Circ. Theor. Appl. 2014, 42, 1154-1171.

24. Yan, J.; Xu, G.; Qian, H.; Xu, Y.; Song, Z. Model predictive control-based fast charging for vehicular batteries. Energies 2011, 4, 1178-1196.

25. Liu, C.-L.; Chiu, Y.-S.; Liu, Y.-H.; Ho, Y.-H.; Huang, S.-S. Optimization of a fuzzy-logic-based five-stage battery charger using a fuzzy-based taguchi method. Energies 2013, 6, 3528-3547.

26. Zhang, S.; Zhang, C.; Xiong, R.; Zhou, W. Study on the optimal charging strategy for lithium-ion batteries used in electric vehicles. Energies 2014, 7, 6783-6797.

27. Robinson, F.V.P.; Chunkag, V. Parallel connection of single-switch three-phase power-factor correction converters for interleaved switching. IEE Proc. Electr. Power Appl. 1997, 144, 423-433.

28. Hsieh, Y.-C.; Hsueh, T.-C.; Yen, H.C. An interleaved boost converter with zero-voltage transition. IEEE Trans. Power Electron. 2009, 24, 973-978.

29. Asubay, S.; Genisel, M.F.; Ocak, Y.S. Electrical parameters of a DC sputtered Mo/n-type 6H-SiC schottky barrier diode. Mater. Sci. Semicond. Process. 2014, 28, 94-97.

30. Mikamura, Y.; Hiratsuka, K.; Tsuno, T.; Michikoshi, H.; Tanaka, S.; Masuda, T.; Wada, K.; Horii, T.; Genba, J.; Hiyoshi, T.; et al. Novel designed SiC devices for high power and high efficiency systems. IEEE Trans. Electron. Devices 2015, 62, 382-389.

(C) 2015 by the authors; licensee MDPI, Basel, Switzerland. This article is an open access article distributed under the terms and conditions of the Creative Commons Attribution license (http://creativecommons.org/licenses/by/4.0/). 